Portland State University

PDXScholar

1990

\title{
Immunology and archaeology : blood residue analysis of three sites
}

Shirley Jo Barr Williams

Portland State University

Follow this and additional works at: https://pdxscholar.library.pdx.edu/open_access_etds

Part of the Archaeological Anthropology Commons Let us know how access to this document benefits you.

\section{Recommended Citation}

Williams, Shirley Jo Barr, "Immunology and archaeology : blood residue analysis of three sites" (1990). Dissertations and Theses. Paper 4124.

https://doi.org/10.15760/etd.6008

This Thesis is brought to you for free and open access. It has been accepted for inclusion in Dissertations and Theses by an authorized administrator of PDXScholar. Please contact us if we can make this document more accessible: pdxscholar@pdx.edu. 
AN ABSTRACT OF THE THESIS OF Shirley Jo Barr Williams for the Master of Arts in Anthropology presented June 15, 1990

Title: Immunology and Archaeology: Blood Residue Analysis of Three Sites.

APPROVED BY THE MEMBERS OF THE THESIS COMMITTEE:

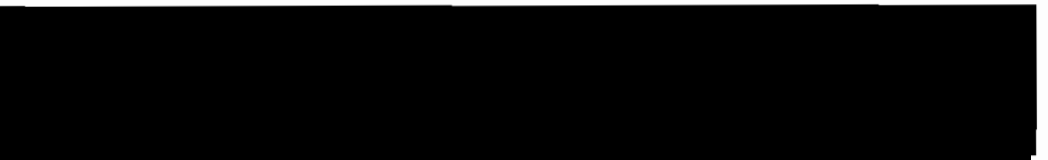

Kenneth M. Ames, Chair

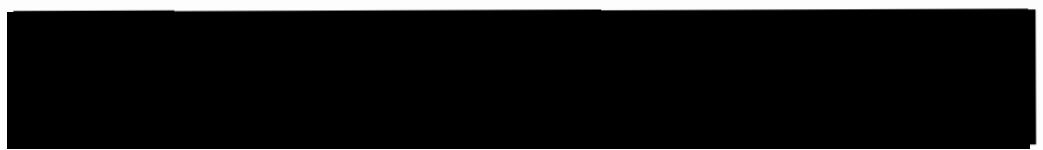

John H. Atherton

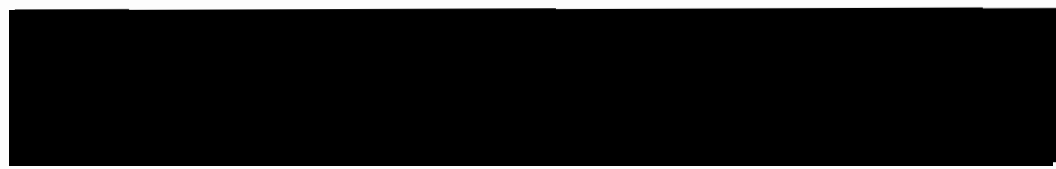

David T. Clark

Cross-over electrophoresis, an immunological method for analyzing blood residues on archaeological artifacts, is tested. Artifacts from three sites were utilized in the testing of this methodology. The sites are the Dietz site in south-central oregon (282 artifacts), Konemehu in northern California (48 artifacts tested for winthrop Associates), and Chimney Shelter in southwestern oregon (3 artifacts from the Umpqua National Forest).

A brief description of each site and its known significance is included. Particular attention is paid to 
the background of the clovis component of the Dietz site, due to its age $(11,000-12,000$ B.P.), and the fact that it is the first site of its kind in the state of oregon. Background information is included on the recent beginnings and significance of blood residue analysis in archaeology, and brief descriptions of other types of tests that have been tried in this new approach to archaeological problems. A very brief and much simplified version of the immunology pertinent to the methodology of cross-over electrophoresis is also discussed. The methodology of cross-over electrophoresis is described in detail.

Results were completely negative from the Dietz site artifacts, but positive results were obtained for avian blood from approximately $1 / 3$ of the artifacts from the other two sites. A discussion of the possible causes for the negative results from the Dietz site, and the significance of the positive results from the other two sites is included. Speculation on the future of blood residue analysis completes the thesis. 
IMMUNOLOGY AND ARCHAEOLOGY:

BLOOD RESIDUE ANALYSIS OF THREE SITES

by

SHIRLEY JO BARR WILLIAMS

A thesis submitted in partial fulfillment of the requirements for the degree of

MASTER OF ARTS

in

ANTHROPOLOGY

Portland State University 
TO THE OFFICE OF GRADUATE STUDIES:

The members of the Committee approve the thesis of Shirley Jo Barr Williams presented May 29, 1990.

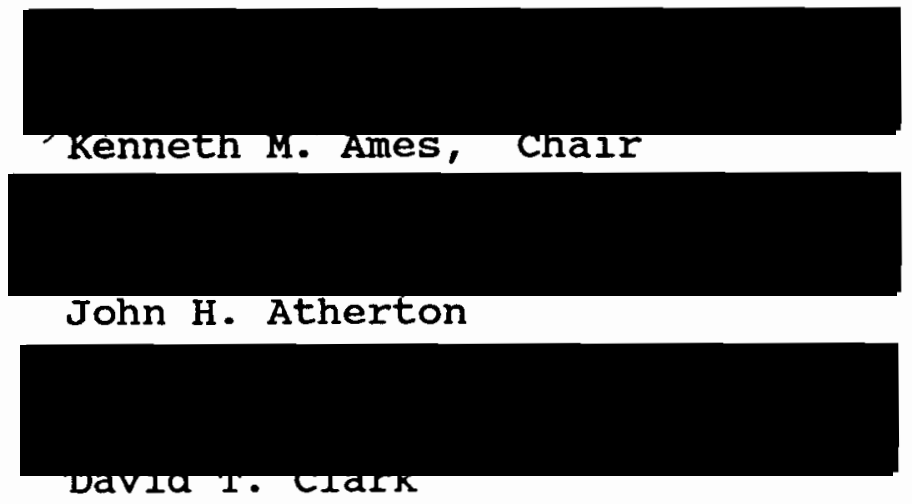

APPROVED :

Kenneth M. Ames, Department Head, Anthropology

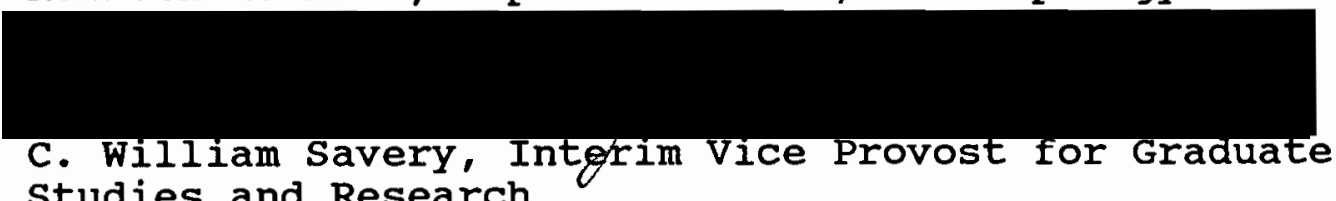

Studies and Research 


\section{ACKNOWLEDGEMENTS}

I have been very fortunate in the kind and quality of help given to me by a number of people. John Fagan was responsible not only for entrusting me with the artifacts from the Dietz site, but for a great deal of support throughout the project. I must thank Margaret Newman for not only showing me how to do the electrophoresis, but for \&the interest and help via phone and letter from the very beginning. Dr. Everett Lovrien gave me free use of the electrophoresis and other equipment, and space and time and help when I needed it. This project would still be getting off the ground without that help.

Dr. Jerold Lowenstein (M.D.) very generously analyzed several of the Dietz site artifacts by RIA, and invited me to San Francisco to learn how to set up the specimens for the analysis of those artifacts. I thank him for both his interest in blood residue analysis and for his expertise.

A note of thanks is due both Vance Carlson of the U.S. Forest Service for the chimney shelter artifacts, and to Katie Winthrop of Winthrop Associates for the Konemehu artifacts.

In the Anthropology Department at Portland State I must thank Ken Ames, my advisor, for his support and advice; Marc 
Feldesman, for his interest and Vincent Sarich's phone number; John Atherton, for Tom Loy's papers which first got me interested in the field, and Ann Bennet for telling me about the contact in Forensics which led me eventually to contact $\mathrm{Dr}$. Lovrien and the lab space needed for the project.

Several people are to be thanked for the donations of various animal blood specimens used for controls. Kay and Justin Edwards, veterinarians at the Eagle Fern Veterinary Hospital in Estacada, oregon supplied goat, horse, rabbit, and extra dog and cat samples. Another veterinarian, Dr. Tesar and his assistant Cydney Miller in Portland supplied rat blood. Avian blood was donated by Bob Sheehy, from a research project at the Oregon Health Sciences University. Mike Briggs of the Wildlife Safari sent elephant, camel, black tailed deer and four horned sheep specimens. Dr. Mike Schmidt, veterinarian at the Portland zoo donated a tube of black bear blood - not an easy thing to come by. A friend and fellow Anthropology student, Dan Sullivan, came up with bovine, sheep, and pig blood from a slaughterhouse. The late Kunta Kittay (feline friend) involuntarily supplied a sample of cat blood as well, after having his ear chewed by another feline.

Dr. Vincent Sarich of the Anthropology and Biochemistry Departments at the University of California at Berkeley gave both an hour or so of his time as well as the antisera 
developed in his lab for elephant and camel, which would have been impossible for me to obtain commercially.

Elinor F. Downs and Debbie M. Gurfinkel both supplied their papers cited in this thesis. Ray Grimsbo, of the Intermountain Forensic Laboratory also supllied me with several papers and other sources for forensic papers.

This paper would have been impossible without the grant for $\$ 300$ from the oregon Archaeological society, and the grant for $\$ 500$ from the Association for Oregon Archaeologists, both of which helped purchase supplies an antisera for the project.

A great deal of thanks is due Monique Cushing-Fournier, a true God-send, who voluntarily assisted me in the last few months of lab work, and whom I now count among my friends. An extra thanks is due to John Fagan and also Jo Reese for putting Monique in contact with me.

I thank my family: my father Joe M. Barr (who also donated human blood for controls after accidently cutting his finger); my mother Helen M. Garhan; sisters Ilene Keister, Cathy White, and Linda Barr-Batdorf; brother Tim Barr. All have given me nothing but love and support throughout this project.

I must give thanks to my unborn daughter (due July, 1990) for giving me even more reason for finishing this in time; but most of all I thank my husband and best friend, Tom Williams, for all of his love and understanding. 
TABLE OF CONTENTS

PAGE

ACKNOWLEDGEMENTS.........................

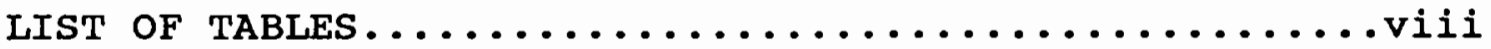

LIST OF FIGURES.........................

CHAPTER

I INTRODUCTION.....................

II $\quad$ BACKGROUND $\ldots \ldots \ldots \ldots \ldots \ldots \ldots \ldots \ldots \ldots$

The Dietz Site/Clovis Background.........4 Konemehu and Chimney Shelter...........

Blood Residue Analysis...............9

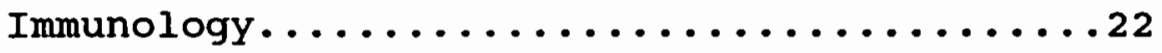

III METHODOLOGY..................... 24

Visual Analysis..................... 24

The Extraction Process..............26

Electrophoresis..................28

Cross-Reactivity Protocol..............41

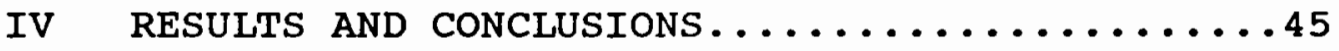

Results..................... 45

Discussion.....................48

Blood Residue Analysis: The Future.......54 
vii

REFERENCES .

APPENDICES

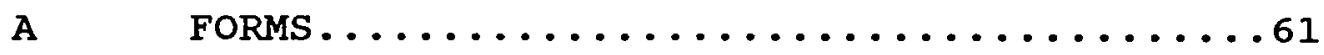

B METHODOLOGY - OUTLINE................. 65 


\section{LIST OF TABLES}

TABLE

PAGE

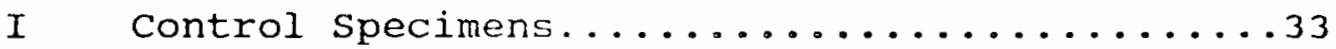

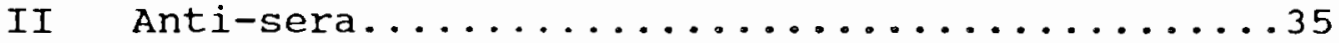




\section{LIST OF FIGURES}

FIGURE

PAGE

1. Clovis Points.....................

2. Double Boiler Set-up for Agarose Gels........30

3. Using Gel Punch To Make Wells in Gel........32

4. Using Vacuum Pipette To Suction Out Plugs

Made in Gel by Gel Punch.............32

5. Filling Wells in Gel with Specimen Samples,

Controls, and Antiserum...............38

6. Placing Wick Material on End of Gel for

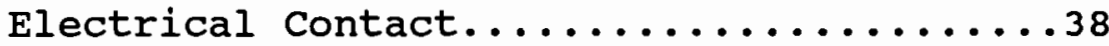

7. Gel is Ready to Run - Complete

Electrophoresis set-up................39

8. Comparitive Results from Konemehu.........46

9. Comparitive Results from Chimney Shelter.....47 
CHAPTER I

\section{INTRODUCTION}

The purpose of this study is to test and expand the methodologies used for analyzing blood residues on archaeological artifacts. This is accomplished by examining and analyzing the blood residues from three sites.

The first and largest of the three sites is the Dietz site in south central oregon. This site includes 282 stone artifacts from several different periods. The oldest of these artifacts are of the clovis type $(11,000$ to 12,000 B.P.). The two smaller sites are Konemehu in northern California (48 artifacts tested for Winthrop Associates), and 3 artifacts from Chimney Shelter in the Umpqua National Forest in southwest Oregon.

The Dietz site is oregon's only known clovis site and is important for that reason alone. This study is the first of its kind done on a large site of this age although Newman (Mehringer 1988.a \& b) has recently completed an analysis using the same methodology, cross-over electrophoresis, on the Richey-Roberts Clovis cache in washington state with positive results.

The detection of blood and other organic residues on 
archaeological specimens is now in its infancy. one of the first successful attempts was by Tom Loy (Loy 1983a). In his initial attempts analyzing those residues - once he had established that they were, indeed, there - he used a technique called hemoglobin crystallization. This method may have some advantages, but it also has serious disadvantages, especially for artifacts of the age of the Dietz site collection. Those advantages and disadvantages will be explained in the next chapter.

One of the biggest potential benefits from analysis of organic residues is not only that obtaining direct information about the fauna of a site is possible, but that it is possible in areas where bone and other organic remains are no longer present. Both Loy (1983a \& b)) and Newman (Newman and Julig 1988) were able to obtain residues from artifacts from boreal forest environments where the extreme soil acidity had long ago dissolved any bone or other evidences of faunal remains that may have originally been part of the site.

After researching possible techniques for analyzing blood residues, I decided that an immunologically based method would be more promising and workable than the hemoglobin crystallization used by Loy. Again, the reasons for this will be explained in detail in the next section. I have used the technique of cross-over electrophoresis (or, countercurrent immunoelectrophoresis, in Turgeon 1990), 
which was adapted for blood residue analysis of archaeological specimens from its original use in forensic medicine by Margaret Newman, now at the University of Calgary, Canada.

The analysis of blood residues by any method is still very new and still primarily experimental. The potential for archaeology is great and no doubt several different methodologies will have to be tried before the dust finally settles on the topic. 


\section{CHAPTER II}

\section{BACKGROUND}

\section{THE DIETZ SITE/ CLOVIS BACKGROUND}

The Dietz site was discovered by a knowledgeable amateur, Dewey Dietz, on his family ranch in the Lakeview Bureau of Land Management District in south-central oregon. Knowing that he had made a significant find, Mr. Dietz brought some of the artifacts to John Fagan - then an archaeologist with the U.S. Army Corps of Engineers - who was the first professional involved with the site. Dr. Fagan remained deeply involved with the site throughout its subsequent excavation, and he was instrumental in making sure the excavation of the site was carried out with some kind of organic residue analysis in mind (i.e., no extensive surface cleaning of the artifacts, limited handling). This type of care greatly improves the possibility of finding whatever residues may still be on the artifacts. Dr. Fagan also did a detailed lithic analysis of the artifacts from the site (Fagan 1988).

Today the area of the Dietz site consists of a shallow, sage-brush filled alkali basin with several faint terraces along the edges indicating former shores of now nonexistent shallow lakes. The detailed geological reconstruction of 
the area by Judy willig (1988) shows that each terrace level can be traced and that the size, depth, and age of the lake corresponding to each terrace can be closely approximated. Most of the Dietz artifacts were surface collected from this large area, and from the flats surrounding the basin. The collection includes several different types of artifacts including windust, Cascade and Desert side-notched as well as Clovis (Barr 1989a).

The Clovis component of the Dietz site was recovered from a single small area of the basin from the $1314.8 \mathrm{ft}$. elevation terrace (Willig 1988). Some were surface finds, but excavation was carried out by students and volunteers from both the University of Oregon and Washington State University. However, the excavation was shallow, not going much below $20 \mathrm{~cm}$. in depth (Willig 1988).

The clovis component of the site initially generated the most interest. Prior to the Dietz site there had been only a few scattered surface finds of clovis points in oregon. As mentioned, Dietz was the first true clovis site discovered in the state.

clovis artifacts are the oldest confirmed evidence of humans in the western hemisphere $(11,000-12,000$ B.P.). They were named for the town of Clovis, New Mexico which was near where they were first found, but clovis sites and points have been discovered all across North America and 
Central America (Fiedel 1987).

The clovis type point is a large (from 3 to 9 inches in length) lanceolate biface and has a concave base with very characteristic flute flakes taken from each side. The bottom and sides of the base were usually ground down slightly to facilitate hafting on a spear shaft. The clovis tool kit also includes gravers, blades, and bone tools, but the type point is quite distinctive (see Figure 1) (Fiedel 1987) .

It has long been theorized that the clovis people relied primarily on large game, particularly mammoth and mastodon. This is based on the association of clovis points with remains of such large animals as the mammoth, the large size of the type points, and that the tool kit seems to be geared towards hunting, preparing and cutting meat, and making spears rather than gathering or processing plant foods.

Debate has grown in recent years as to what extent the clovis people also hunted smaller game and to what extent they may have exploited plant foods. The argument along these lines is based on the idea that the initial impression of the clovis people's primary reliance on large game may have been less than completely accurate. The greater percentage of preservation of remains of large animals could possibly have skewed the sample available, and given us a false impression of the resources utilized by the 


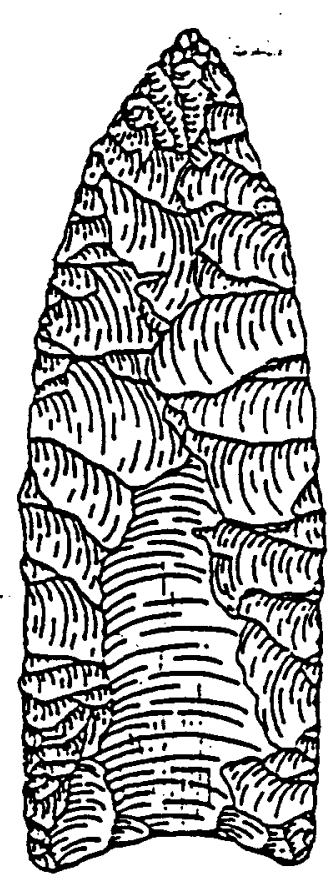

a.

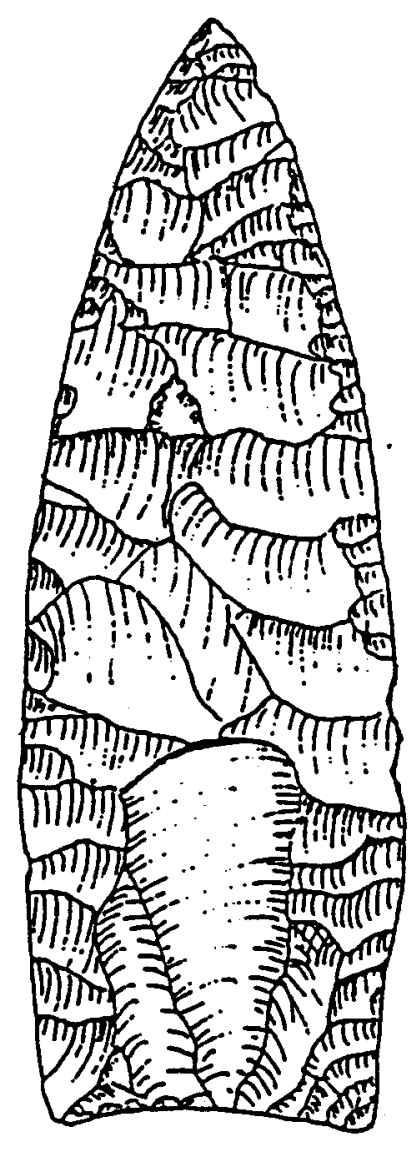

b.

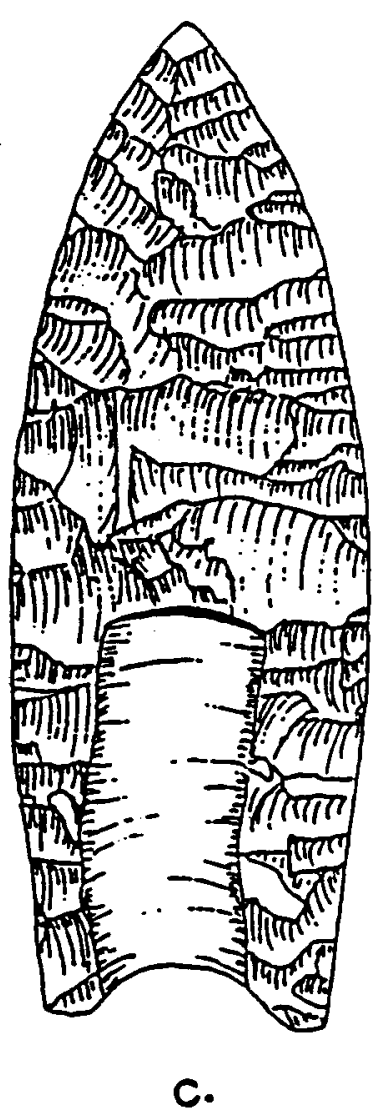

Figure 1, Clovis Points. A. Is from the Dietz site, Orégon (Willig 1988) specimen B. is from Blackwater Draw, New Mexico (Fiedel 1987). Specimen C. is from the Vail site, Maine (Fiedel 1987). 
Clovis people (Fiedel 1987).

There is some difference of opinion between Fagan (1988) and willig (1988) on the emphasis of large game hunting of the Dietz site Clovis people. Fagan sees a greater emphasis on large game utilization than does willig, and willig sees a greater possibility of a connection between the clovis and the various stemmed point peoples who occupied the area after the Clovis occupation.

It was hoped that the blood residue analysis would shed some light on the debate concerning the clovis lifeways, and it may very well do so in the future. Unfortunately, the residue analysis of the Dietz site artifacts can add nothing to the debate at this time, but this will be more fully explained in the Results section of this paper.

\section{. KONEMEHU AND CHIMNEY SHELTER}

Konemehu is a small, forest site in northern California. The site is from approximately 500 to 800 years old, and therefore pre-contact. The majority of the artifacts are obsidian, although some are made of chert, and they average less than $3 / 4$ of an inch in length. I did the analysis of this site for Winthrop Associates, a contract archaeology firm in Ashland, Oregon.

Chimney Shelter is a rockshelter in the Umpqua National Forest in southwestern oregon. The three chert artifacts 
from this site are from a test pit. The site is 1000 or more years old, and as a rockshelter, is well protected from the elements. There is but a limited amount of ethnographic evidence on the Cow Creek Indians who inhabited this area of Oregon, and this site may help fill in some of the missing information about them (Minor and Musil 1990). Like the artifacts from Konemehu, these artifacts are also small in size.

\section{BLOOD RESIDUE ANALYSIS}

The analysis of blood residues on stone is quite new. Very little has been published on the topic as yet. Just prior to Loy's work (1983a), some work in paleontology indicated that some proteins may last very long periods of time. Wyckoff (1972) demonstrated the preservation of ancient proteins in ancient bone and shell, and Hedges and Wallace (1980) showed that collagen is still present in some dinosaur bones. Lowenstein (Lowenstein, personal communication, 1987) has also obtained species specific results from dried urine albumin in rodent nests from 20,000 year old carbon 14 dated cave deposits using a technique called radioimmunoassay, or RIA (methodology in Lowenstein, 1983). This last case is particularly interesting in regards to cross-over electrophoresis, the technique used here, because albumin is one of the plasma proteins 
identified by that method; it indicates that 20,000 year old proteins may be present on archaeological artifacts as well.

Also prior to Loy's work, Brieur (1976), Broderick (1979), and Shafer and Holloway (1979), detected blood and other residues on archaeological artifacts. Brieur (1976) identified residues on artifacts from two prehistoric rock shelters in Chevelon Canyon in Arizona using a microscope. This microscopic identification was geared towards plant residues in particular. Simple chemical tests were then used to try to differentiate plant and animal residues. The test used for blood residues was the benzidine test, performed by the state of California Department of Justice Crime Laboratory. Only one mano (a hand held stone tool for grinding seeds or corn into flour) reacted for blood, but as Brieur states..." A presumptive test such as the benzidine test for blood can hardly be considered conclusive and only suggests the presence of bloody residues." (Brieur 1976). Brieur's work does indicate interesting lines to follow in the future in identification of plant residues, but offers little in blood residue analysis.

Broderick (1979) attempted to follow up and expand upon Brieur's work. Broderick used ascending paper chromotography to separate and identify amino acids from unwashed slate knives that had been excavated in Hope, British Columbia. Like the Dietz site artifacts, these 
artifacts were not washed and handing was done only while wearing gloves. Amino acids were identified, but Broderick did not attempt a quantification which might lead to identification of specific animal or plant groups.

Shafer and Holloway (1979) also mentioned Brieur as background for their work. In this study, artifacts from a dry rockshelter in southwest Texas were studied by microscope in order to identify organic fibers and residues. Some animal and plant fibers were identified, and phytoliths - crystalline substances left from plant cells - were also identified and correlated to known groups, such as the yucca family.

All of these studies showed enough potential to warrant further investigation, and may eventually prove to be useful, especially in the area of plant residues. But, Loy (1983a \& b) was the first to verify blood residues on artifacts, to have species specific results, and to show the real potential of this kind of study for archaeology.

Loy's (1983a) original methodology included testing the artifacts first with a simple, commercial, clinical laboratory dipstick to test for hemoglobin in solution (Chemstrip), a microscopic analysis, and then the hemoglobin crystallization. The only portion of his initial methodology retained for this study is the microscopic analysis. 
In his initial work, Loy (1983a \& b) used the dipstick test to establish the presence of blood on the tools he was testing. This was critical in the early stages of this type of analysis; it established the possibility of blood residues remaining on stone tools in testable amounts at all, something Loy believed to be true after seeing residues on specimens with use-wear polish (Loy, personal communication, 1987). The dipsticks show a reaction with the heme portion of the hemoglobin molecule, and this reaction is quite sensitive; it can detect $10^{-9} \mathrm{gm}$. (Gurfinkel 1987). But the dipsticks, like the benzidine test, only indicate the possible presence of blood and nothing else. It can also give false positive results from other substances in the soil, such as bacteria and chlorophyll (Gurfinkel 1987, Tennant and Tennant 1987, Custer et al. 1988).

I elected not to use dipstick testing for this study. The possibility of blood remaining on a stone tool has been established, and it is unnecessary to demonstrate it again. Residues left on archaeological specimens are irreplaceable and of a very limited quantity if present at all. It seems unnecessary to use up such a limited resource merely to indicate that blood of some kind might be present when testing with the same amount of specimen could tell what kind of animal the blood was from. 
Loy (1983a \& b) used hemoglobin crystallization to try to determine the source of the blood residues on artifacts. This technique had previously been used to determine the source of blood ingested by adult female mosquitoes and other arthropods with similar diets (Washino 1977). Hemoglobin crystallizes into species specific patterns in the presence of certain chemical buffers, and those differences in crystal pattern are based upon random mutations in the structure of the hemoglobin molecule of different species (Loy 1983a). Although this kind of reaction had been known since early in this century (Reichert and Brown 1909), Washino's (1977) use of it for determining the host animals of arthropod meals, and Loy's use for archaeology were the first to utilize it for any practical purpose.

Hemoglobin crystallization's seemingly greatest advantage is also, paradoxically, its greatest disadvantage, particularly for a study of artifacts as old as those of the Dietz site. The crystal patterns are not just species specific, they are extremely species specific. In other words, even closely related species may have quite different crystal patterns, and no comparisons are possible unless one has control samples from the exact species, and this may not always be possible. The great age of the clovis artifacts from the Dietz site makes this kind of specificity 
impractical. Some of the animals on which the points may have been used are now extinct, making comparitive crystals all but impossible to obtain. These animals include the very ones, such as the mammoth, that the clovis people may have exploited and which would be most interesting to detect. Among extant animals such as deer or rabbit, minute changes in the hemoglobin structure may have occurred in the last 11 or 12 thousand years. Even in well preserved blood some denaturing occurs, especially the hemoglobin (Sensabaugh et al. 1971), and the effect of this on the crystal patterns is unknown.

Loy (Loy and Wood 1989) has recently admitted this drawback. He has had interesting success in developing a comparative crystal pattern from the bones of an extinct bovid, the auroch (Bos primigenius) from the early neolithic site of Cayönü Tepes in Turkey. This was matched to an unknown crystal pattern from the site. This shows potentially, at least, that hemoglobin crystallization could be used when dealing with artifacts that had been used on extinct species, although even then it would be of limited use. Interestingly, in this same paper Loy used an immunological technique - a dot blot test for detecting human blood - to back up the hemoglobin crystallization test for human blood.

An alternative methodology, and the one used for this 
study, was adapted for archaeological use by Margaret Newman. She came to anthropology after having worked as a medical technologist, and had a more extensive background in the types of tests that might be adaptable to archaeological work than did Mr. Loy.

She uses a simple type of immunoelectrophoresis, called cross-over electrophoresis, that had been used by crime labs for many years to differentiate human and animal bloods. There are many other types of electrophoresis used in medicine, but forensic medicine has naturally been more concerned with animal blood, and with old blood specimens than any field other than archaeology.

The results of cross-over electrophoresis are somewhat less specific than hemoglobin crystallization - at approximately the family level rather than species - but the technique has several advantages. First, it is very sensitive; it can detect as little as 10 nanograms (10-6 grams) of hemoglobin antigen (Culliford 1971, Crowle 1973). It also uses very small amounts of specimen - 3 to 5 microliters per Family group tested.

It is relatively rapid; the electrophoresis itself only takes about 40 to 45 minutes, and that is with 24 specimens per gel. Washing, drying, and staining the gels takes a little more time, but the end result is a clear, stable, permanent record of the test run - also an advantage. 
In 1986 John Fagan (Fagan, personal communication, 1986) chanced to meet Margaret Newman at the Society for American Archaeology conference in Toronto, and discovered that she had earlier worked with Tom Loy, but was beginning to work on a different type of analysis than the hemoglobin crystallization Loy had used. I contacted her and discovered that she was preparing to move from victoria B.C. to Calgary, Alberta, and I made rapid preparations to go talk with her in person, as well as to talk with Tom Loy, then at the Provincial Museum in Victoria.

The trip was very productive. Ms. Newman graciously gave me a 'crash course' in cross-over electrophoresis while she was packing and finishing up her last few tests only a few days before she was to move. I was impressed with her technical expertise and professionalism (not to mention her kindness in taking the time to show me her methodology when she herself was under a lot of pressure), and I was also impressed with the cross-over electrophoresis. Impressed enough, especially when I realized that it was within my own range of abilities to do, that I was convinced to use it for the residue analysis of the Dietz site.

other types of tests have been tried for detecting blood residues. These include another type of electrophoresis, SDS PAGE (sodium dodecyl sulphate-polyacrylamide gel electrophoresis), done by Diane Gurfinkel (1988). 
Gurfinkels's final conclusions indicate that..."blood may indeed be sufficiently stable to survive on archaeological material under certain circumstances". Gurfinkels's methodology was not immunologically based, but more on this point later.

Although not using an immunologically based approach herself, Ms. Gurfinkel very kindly put me in contact with Dr. Elinor Downs (M.D., retired) who had experimented with a simple immunological test, the Ouchterlony procedure. The ouchterlony procedure is a fairly simple form of immunodiffusion..."based on the classical antigen-antibody precipitin reaction." (Downs 1985).

Before applying the procedure to actual artifacts, Dr. Downs experimented with blind tests on self made experimental lithic flakes, with very accurate results. She had less luck detecting blood via microscope or with dipstick tests on actual artifacts. She tested specimens in several museum collections from the northeastern and southwestern United States. She found visible, testable residues on only 3 artifacts, all from the Southwest. These results may not seem exciting, but one must keep in mind that not only had the artifacts been cleaned, but many had been on the shelf for up to one hundred years. It is promising that any residues were detected under the circumstances; particularly since the ouchterlony procedure 
is probably one of the least sensitive of immunologically based procedures.

Newman's dissertation project (Newman, personal communication, 1987) with cross-over electrophoresis was an analysis of the artifacts from Hidden Cave, New Mexico also a museum collection. Cross-over electrophoresis is based on the same kind of precipitin reaction, but the added boost from the electrical current of the electrophoresis reduces the amount of specimen needed and increases the sensitivity and speed of the reaction (less than an hour as opposed to 24 to 48 hours). Newman has also had quite good success with the artifacts from several sites such as the Richey-Roberts Clovis cache (Mehringer 1988a \& b), the Cummins site in ontario (Newman and Julig 1988), the Capitan site (Newman, personal communication, 1988), and the carson Sink sites in Nevada (Newman, personal communication, 1988).

The University of Pittsburg has been working with yet another immunological technique - enzyme immunoassay or EIA - with good results (Hyland et al. 1989, and Hyland et al. 1990). Newman has also mentioned that she will be looking into this technique in the near future, if not already (Newman, personal communication, 1989). EIA can be highly specific, is very sensitive, and may very well turn out to be a useful tool for archaeology. It does use more specimen than does cross-over electrophoresis - 100 microliters as 
opposed to 3 to 5 microliters.

Loy has used a related technique as a double check for the hemoglobin crystallization in his most recent work (Loy and Wood 1989, and Loy et al. 1990). Loy used a dot-blot test, which is based on the same enzyme reaction as EIA, and has a similar possible sensitivity in the picogram range (10 $9 \mathrm{gm}$.$) . It is not yet applicable for testing for more than$ a handful of animal types, since it uses commercialy available kits, but the equivalent could be developed in a University laboratory. Both the University of Pittsburg group and Margaret Newman at the University of Calgary are beginning to work on this problem.

Dr. Jerold Lowenstein (M.D.) of the University of California Medical school in San Francisco has successfully used an equally, if not more, sensitive method, RIA (radioimmunoassay) in an application to taxonomic problems of extinct species, among other projects (Lowenstein 1983). He has been interested in the development of blood residue analysis from the very beginning; having used RIA as a check for both Loy's and Newman's work, as well as some of my own. (Oddly enough, I had no knowledge that he knew either Loy or Newman until after I had contacted him for a completely different reason.) He not only ran some of my artifacts, but extended an invitation to come to san Fancisco to learn a little more about how to set up the RIA test itself. 
I accepted the invitation, and had the opportunity to help set up the RIA run for some of the Dietz artifacts. The results were unusual, and less than had been hoped. Almost all of the original 25 specimens (23) tested by RIA turned out to have extremely high human results. There were a few positive results from animals other than human, but these were invariably on those specimens where the human results were particularly high. These results may have been cross reactions rather than true reactions, although it is difficult to tell after the fact.

Additional specimens were sent to $\mathrm{Dr}$. Lowenstein for testing. It was originally thought that the high human results were from handling, but one of these later runs produced an equally high human result on a specimen of the ammonia solution used on the artifacts sent as a blank control. This showed that there was some source of contamination in the ammonia solution. It is still a perplexing problem; the source of the contamination was never discovered. A new ammonia solution was used, but this too was contaminated. The only thing left to try was to carefully wash all weigh boats (used in processing the artifacts) and glassware with a soap (RB 50) used for washing RIA equipment, even if they were supposed to be clean. It was discoverd later that the plastic weigh boats may have been exposed to organic lubricants in their 
manufacture (David Sesser, microbiologist, Oregon Public Health Laboratory, personal communication 1990), and this is one possible source of the problem. Gloves were used to insure against any possibility of new contamination of the artifacts. The final result of all of this was that the extreme sensitivity of the RIA process gave possible positive results (other than human) on a few specimens but it was impossible to verify them due to this contamination.

It would have been prohibitively expensive to do the entire Dietz collection by RIA. The process uses costly materials and requires 20 microliters for each test (although Dr. Lowenstein graciously did not charge me for the samples that he tested.). RIA requires special equipment; a gamma counter and radioactive materials that could put it out of the budget range for archaeology. But its potential as an accurate species specific test is very exciting. At this time I see RIA, or EIA, or something like it, as a way of refining the more generalized results that cross-over electrophoresis can provide.

More research is definitely needed into the the strengths and weaknesses of the various tests. After seeing Newman's work and the other, more highly technical immunological approaches that have begun to be examined, an immunological path seems the most logical one to follow. 


\section{IMMUNOLOGY}

Some background on immunological reactions is in order. This is an extremely simplified version of a small portion of the very complex field of Immunology, but this should suffice for the purposes of this study. Immunological reactions all stem from a living organism's reaction to a foreign (non-self) substance - usually a protein. This foreign substance is the antigen. One kind of immune reaction, for example, is to sneeze in the presence of certain kinds of pollen. Another, less visible immune reaction is that the organism will build up an 'antiantigen', or antibody as it is more correctly called, to counteract the antigen. When the antibody is isolated and purified, one then has the anti-serum to the original substance. In other words, the anti-serum is a substance that will react in the presence of the antigen. Although discovered as long ago as 1901 (Gaensslen 1983), what is still one of the most studied and most useful and most used immune reactions is the antigen/antibody reaction. This reaction occurs when an antigen and antibody to the same or closely related species are combined in the proper medium (such as an agarose gel) they then react to form a visible precipitate in the form of a white line in the medium. If not at least closely related species, no precipitate forms. Cross-over electrophoresis merely combines this 
antigen/antibody precipitate reaction with the speed and separating powers of electrophoresis.

Hemoglobin crystallization was known to, and abandoned by forensic research many years ago (Gaensslen 1983). To be fair, Loy's most recent work with extinct species, and hemoglobin crystallization's application as a field test keep it in the running, but it still remains a rather unwieldy and fairly subjective procedure.

As Gaensslen (1983) states about forensic medicine... "Most current methods in common use for determining species of origin are immunological ones.". For most of this century, forensic medicine has been in search of better, more practical, and less expensive ways of determining the species of origin of blood stains, even very old ones. This background of knowledge and experimentation is something which archaeologists interested in analyzing blood residues should take heed.

I am convinced that an immunologically based method (or methods) for the analysis of organic residues on archaeological artifacts will eventually prove to be the most sound and useful one for Archaeology. That is why I chose Newman's cross-over electrophoresis for the analysis of the blood residues on the Dietz site collection. 
CHAPTER III

METHODOLOGY

VISUAL ANALYSIS

A binocular dissecting microscope with magnifying power up to $45 \mathrm{X}$ was used for the visual analysis. Red cells, per se, are not visible at this level of magnification, but gross residues and fibers are.

The visible recognition of red cells is not necessarily very useful. One can, if conditions are ideal, determine whether the blood under study is mammalian or not by the absence of nuclei in the red cells; all mammal's red cells are non-nucleated and non-mammals have nucleated cells. There are some minor exceptions - newborn mammals, including humans, often have a few nucleated red cells (Andrew 1965). However, the uselessness of red cells for identification beyond that level has been well established in forensic literature for many years (Gaensslen 1983). Before the antigen/antibody tests were developed in the early 1900's, red cell comparisons were considered as a possibility in determining species, but the technique had been completely discarded before the century was 10 years old (Andrew 1965, Gaensslen 1983).

Loy (1983b) identified a fish species by comparing the 
size and shape of the red cell nuclei. One must emphasize, however, that this was a non-mammal and that such specific identification is the exception rather than the rule, particularly on archaeological specimens where visibly identifiable red cells are not likely.

Loy, seemingly, visually detected some red cells on artifacts, but it was decided after unsuccessfully examining several of the Dietz site artifacts for red cells that it was unlikely that any visible cells would remain after 12,000 or more years. Any remaining cells would be in cracks or crevices, and then would be extracted in the next step in the procedure using an ultrasonic cleaner. Therefore, the visual analysis of the Dietz site artifacts was limited to relatively low power examination for possible areas of residues.

Another reason for using a relatively low power microscope is that the artifacts do not have nice flat surfaces like microscope slides. The dissecting microscope's depth of field is greater than that of a higher powered instrument. A fairly thorough examination of the entire surface of an artifact can be done within a reasonable amount of time. Residues are often visible and these are noted on the artifact analysis sheet made for each artifact (see Appendix I for samples of forms used in the study). Just before doing the microscopic analysis, an 
outline of each side of the artifact is made on this sheet.

A note about the outline drawings of the artifacts; I started out doing fairly detailed drawings of each artifact, but eventually realized that such detail was both time consuming and totally unnecessary, however aesthetically pleasing it may have been to do. A simple outline gives enough information to differentiate the two sides of the artifact and make it possible to note areas of interest on each side.

Even a cursory visual examination of the Dietz artifacts showed considerable difference between the two sides in thickness and pattern of residues (and dirt). The outline drawing was a simple way to indicate which side was tested. On large pieces, such as many of the Dietz artifacts, the approximate area of extraction was noted on the outline drawings on the sheets as well. The solution used for extraction often covered the entire side of smaller pieces, and this was also noted on the form.

\section{THE EXTRACTION PROCESS}

organic residues were extracted from the artifact's surfaces with an ultrasonic cleaner and a 5\% ammonia solution. Newman used the ammonia solution because it had been shown in forensic work to be more effective in lifting proteins from old blood stains than 
either distilled water or saline; the other most common solutions used for that purpose (Kind and Cleevely 1969, Dorrill and Whitehead 1979).

The ultrasonic cleaner is half filled with water and an artifact is placed in a pre-washed plastic pan. The weigh boats used to measure chemicals are inexpensive and work quite well for this purpose (after first being washed to remove any possible contaminants). The side of the artifact to be tested is placed down in the pan and a measured amount of the ammonia solution is injected underneath with a pipette as closely as possible to the areas of interest. Usually 500 microliters (.5 milliliters) of the solution was used on the Dietz site artifacts, but it was necessary to use less, 300 microliters, for some of the smaller pieces. This latter amount was used for all 48 of the Konemehu artifacts and the three from chimney shelter, due to the small size of those artifacts.

With smaller artifacts the solution spreads out, covering the entire surface. On very small ones, it comes up onto the other side as well. This was the case with almost all of the Konemehu artifacts. This is a problem if one desires to keep one side clean as a control or for future research on the same artifacts (Barr 1989b).

The artifact is placed in the ultrasonic cleaner it was for approximately five minutes. The solution is then drawn 
off and stored in a small plastic tube. I used 1.5 milliliter plastic microcentrifuge tubes with attached caps. The extracted residues can then be stored in freezer for an indefinite period of time, or refrigerated if precessing is done immediately.

The artifacts were handled with either a pair of tweezers, or while wearing a pair of nylon gloves. Nylon has a minor advantage for this work in that if any small fibers come off they look distinctly different from natural fibers under the microscope. Rubber gloves were ruled out because the talc or other powdered lubricants (many of which are organic) used in them could contaminate the artifacts.

\section{ELECTROPHORESIS}

The first step in the electrophoresis process is to make an agarose gel. Agarose is a common biological laboratory medium derived from seaweed; several different kinds are available, each with somewhat different properties. The most critical factor for cross-over electrophoresis is that the agarose must have a high electroendosmosis rating, or EEO. This effects the movement of fluid through the gel; the desired effect in cross-over electrophoresis. The gamma globulins (IgG) in the antiserum move toward the cathode, and albumin, alpha (IgA) and beta globulins (IgE) in the specimen move towards the anode (Culliford 1971). A high 
EEO makes this feasible. For this study I have used Sigma type III, III-a, and seakem high EEO agarose, and all work equally well.

The agarose, when prepared, is about the consistency of Jell-o and is prepared in somewhat the same way. It comes as a white powder and .2 gram of this powder is mixed with 20 milliliters of barbital buffer (also from sigma Chemical), which is a clear liquid, for each gel. This mixture is brought to a boil in a double boiler (see Figure 2) for several minutes and is then immediately (and carefully) poured onto a pre-prepared piece of Gel Bond on a pre-warmed, level glass plate (A carpenter's level is used to test the area where the gel will be poured.). Gel Bond (FMC Corporation), or electrophoresis film, is a plastic, agarose coated product manufactured as a base for gels (other companies will call it by different names). The gel size used is $100 \mathrm{~mm}$ by $125 \mathrm{~mm}$, following Newman's specifications (personal communication, 1987). The gel takes on a slightly milky appearance after a few minutes as it solidifies and cools. Once cool the gel is then stored in a humid chamber - which is an impressive way to describe a plastic box with a tight fitting lid and a couple of damp paper towels in the bottom. The gel must be refrigerated at least over night before use, and is best used within a few days, but can be kept for a month or more. Before using the 


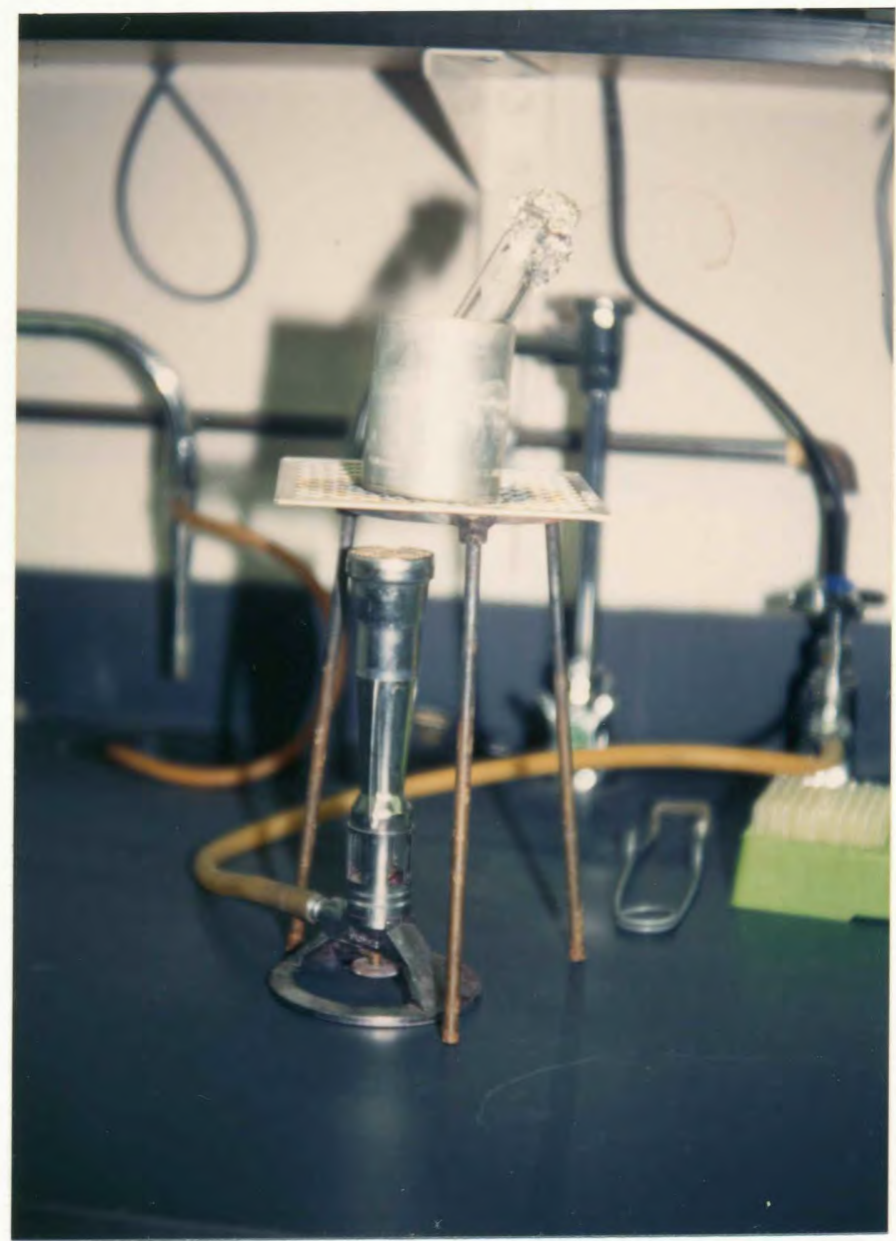

Figure 2. Double boiler set-up for agarose gels. 
gel, holes are punched out with a small metal gel punch (see Figure 3) to form pairs of wells, $5 \mathrm{~mm}$ apart, and the plugs are then suctioned out with a vacuum pipette (see Figure 4). Each gel has 32 pairs of wells, and a typical run will be 24 specimen samples plus four positive and four negative controls. A single antiserum is used per gel. There are four columns of these pairs, and the last two pairs of each column are the positive and negative controls. For example, if one is testing with bovine antiserum (that is, antiserum that will react with bovine serum) the positive control wells are filled with specimen prepared from dried bovine blood and the same ammonia solution used to prepare the artifact samples. In the negative control wells one uses a solution made from the kind of animal in which the antiserum was produced - usually rabbit or goat (Newman and Julig 1988).

The control specimens were obtained from a number of different sources and on a fairly wide assortment of animals (see Table I). These included: african elephant, camel (dromedary), blacktail deer, and four-horned sheep from Wildlife Safari in southern oregon; horse, goat, dog, cat, rabbit, and rat from two local veterinarians; cow, sheep and pig blood acquired by a friend from a slaughterhouse; black bear blood from the Portland $\mathrm{zoo}$; chicken blood from a 


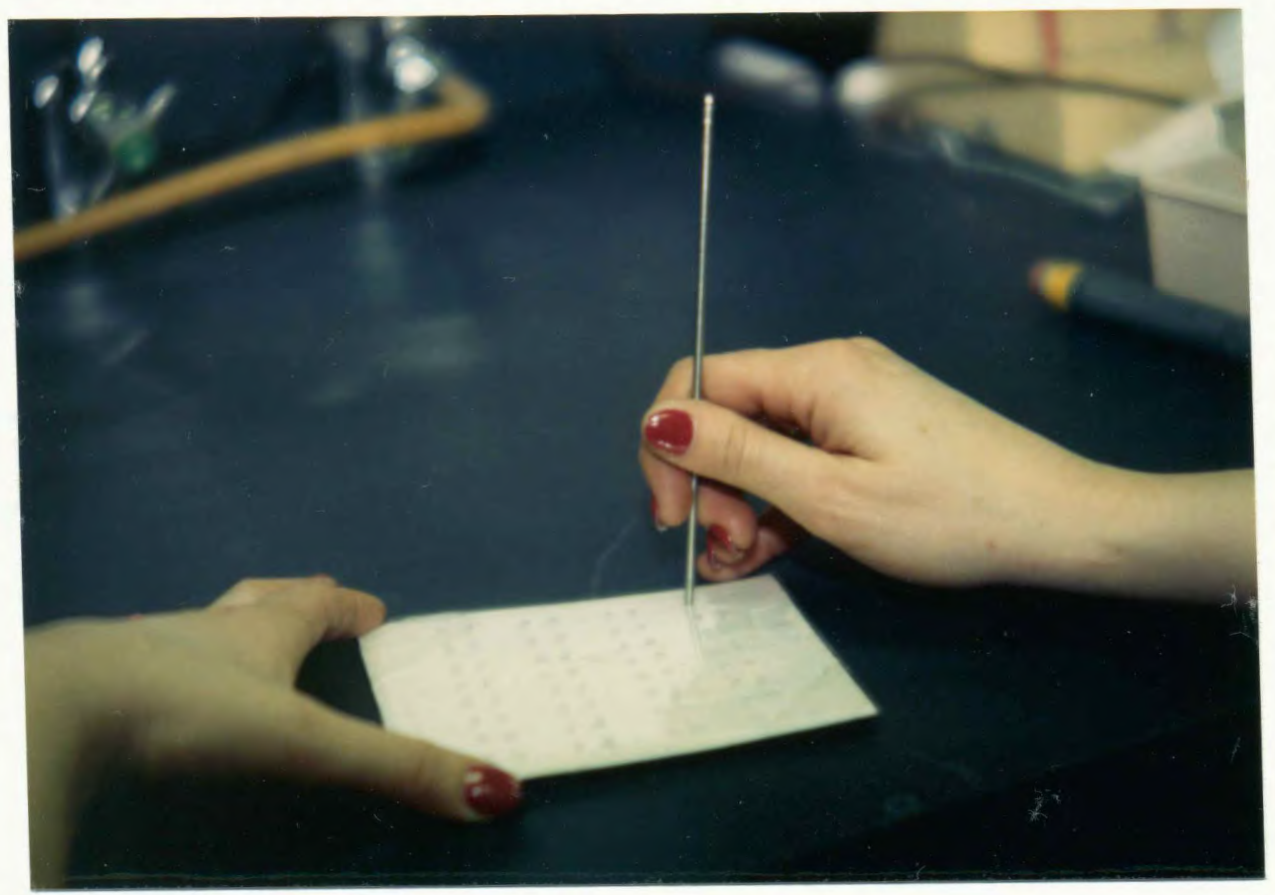

Figure 3. Using gel punch to make wells in gel.

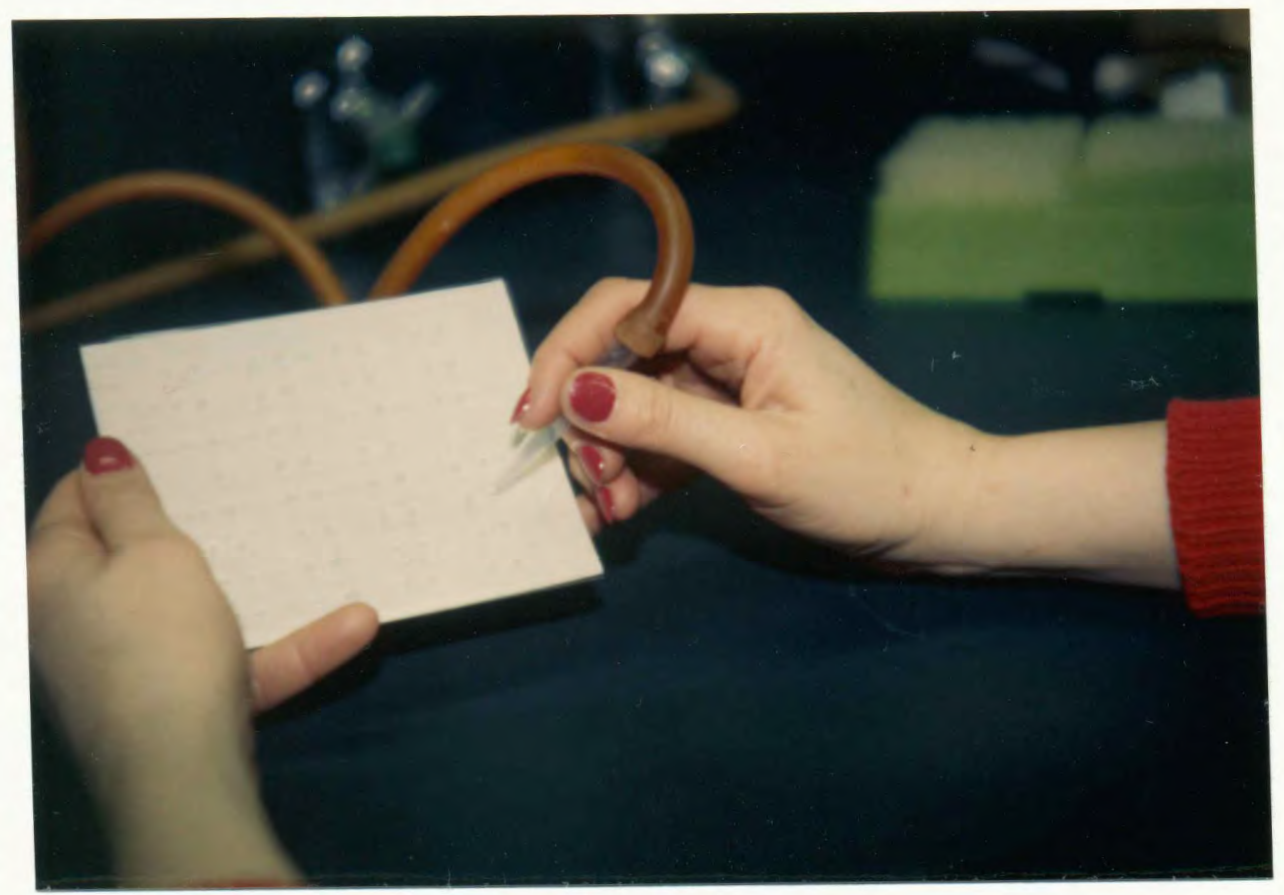

Figure 4. Using vacuum pipette to suction out plugs made in gel by gel punch. 
TABLE I

CONTROL SPECIMENS

TYPE OF ANIMAL SOURCE

Bear

Camel

Cat (1)

Cat (2)

Chicken

Cow

Deer (Blacktail)

Dog

Elephant

Goat

Horse

Human (1)

Human (2)

Pig

Rabbit

Rat

Sheep (1)

Sheep (2 -Four Horned)
Portland Zoo

Wildlife Safari

Eagle Fern Veterinary

Hospital

Personal Pet

Oregon Health Sciences University

slaughterhouse

Wildlife Safari

Eagle Fern Veterinary

Hospital

Wildlife Safari

Eagle Fern Veterinary Hospital

Eagle Fern Veterinary Hospital

self

Joe M. Barr

Slaughterhouse

Downtown Veterinary Clinic

Downtown Veterinary $\mathrm{Cl}$ inic

slaughterhouse

Wildlife Safari 
research project at oregon Health Sciences University; cat blood from my pet cat (after he had been in a fight); and human blood from my father, Joe Barr, who cut his finger and asked if I could use the donation for my project.

For the analysis I chose an assortment of antisera to reflect the possible faunal components of the sites and their environs (see Table II). They were bear, deer, dog, cat, cow, sheep, chicken, rat, goat, rabbit, human, horse, pig, camel, and elephant for the Dietz site. The elephant, camel, pig, and horse were deleted from the analysis of the artifacts from Konemehu and Chimney shelter. As mentioned earlier, the antisera will react with proteins from all closely related animals, and from both modern and extinct species. For example, chicken antiserum was used to represent all avian species. The horse, pig, elephant, and camel were used for animal groups which are no longer native to the area around the Dietz site, but may have been utilized by the clovis people (Fiedel 1987). Those same antisera were deleted from the analysis of the other two sites because extinct species represented by those antisera were not a factor at those much younger sites.

All but two of the antisera were purchased from commercial sources. The two non-commercial antisera, elephant and camel, were kindly provided by Dr. Vincent Sarich of the University of California at Berkeley. 
TABLE II

ANTI-SERA

SOURCE

MADE IN :

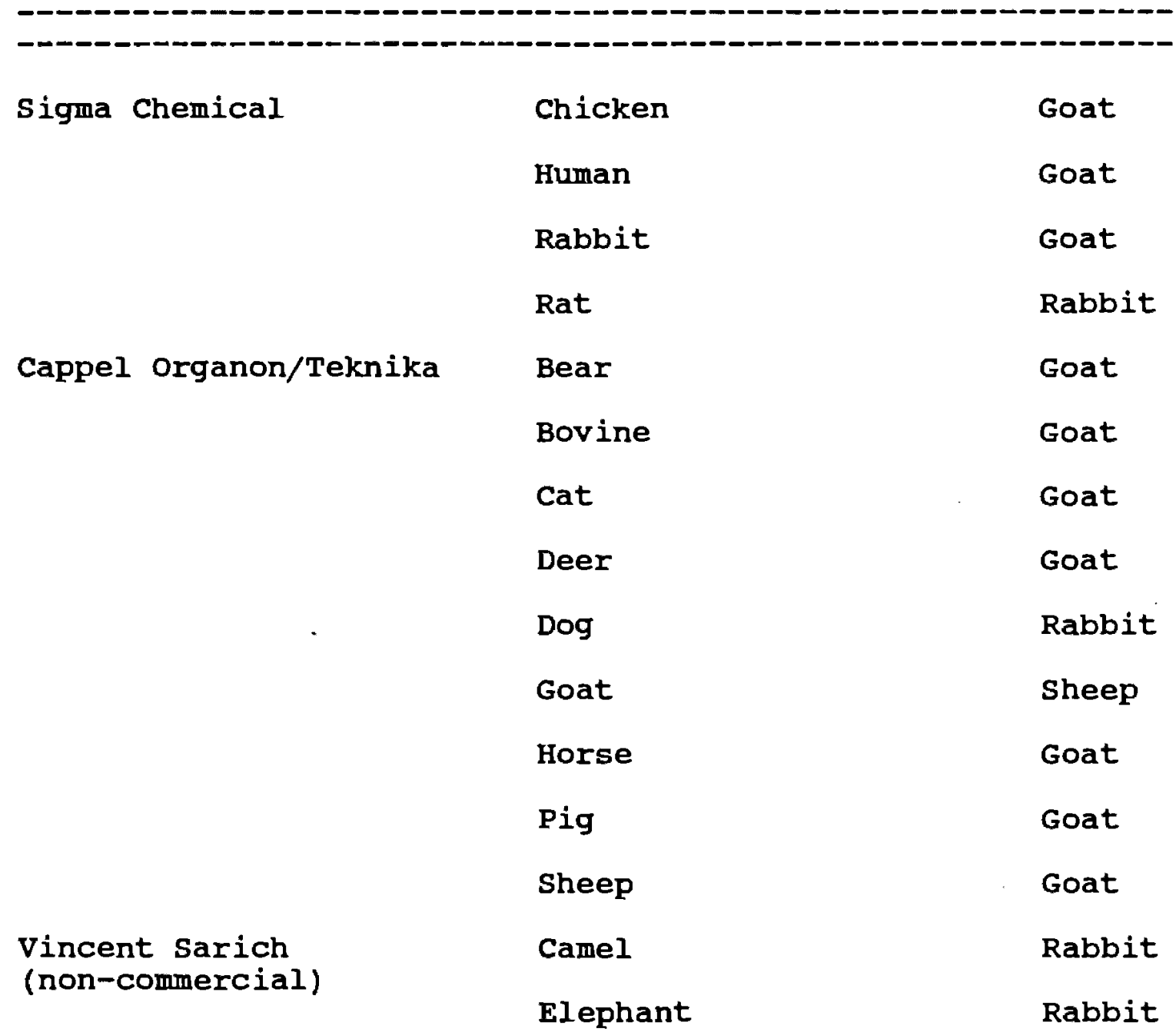


The extra effort to obtain the non-commercially available elephant and camel antisera was made because the only identifiable faunal material found at or near the site included a few mammoth teeth and a camel bone (Fagan 1988, willig 1988). The long established association of clovis material with mammoth bones at sites across the country made the inclusion of elephant antiserum important, particularly since Prager, wilson, Lowenstein and Sarich (1980) demonstrated the reaction of elephant antiserum and mammoth protein by both ouchterlony immunodiffusion and RIA.

Anti-sera were purchased from two other sources, sigma Chemical and Cappel organon/Teknika. After trying some from both sources, it was determined that the forensic antisera from Cappel were more desirable for this project, even though more expensive. The cappel forensic anti-sera are given extra treatment (pre-absorption) to prevent crossreactivity with unrelated species. For example, bovine antiserum from cappel reacted with controls from bovine and slightly with horse. The whole serum bovine antiserum from Sigma reacted with bovine, sheep, goat, horse, four-horned sheep, deer, and camel to various degrees. Newman used Sigma IgG heavy and light chain antisera, and this may have improved her results.

For the final analysis of the artifacts only chicken, rat, rabbit, and human antisera from Sigma Chemical were 
used. The rest, with the exception of elephant and camel from Vincent Sarich, were from Cappel organon/Teknika (see Table II, pg.35). Cappel did not have horse and goat forensic antisera, however, and for those two Cappel's IgG Heavy and light chain antisera were substituted. Unfortunately those two did not react at all with the control specimens for horse and goat, and they were dropped from the study due to time constraints.

When preparing a gel for electrophoresis, the sample wells are filled first, then the controls, and then the anti-serum (see Figure 5). Each well contains approximately 3-4 microliters and filling the wells requires a steady hand, good lighting, and good eyesight. When the Gel bond is first cut to size a small piece of the top left corner is cut off to mark the anodal end of the gel before pouring the agarose, since only one side of the plastic is coated with the bonding material (one can tell because one side is hydrophobic - water beads up - and the other side is hydrophyliic). The samples and controls go in the wells nearest the cathode, and the antiserum in those nearest the anode.

As soon as the gel is filled it is electrophoresed for 40 to 45 minutes, depending on the equipment used, at 130 volts. The same barbital buffer used to make the gels is used in the electrophoresis troughs (see Figures 6 and 7). 


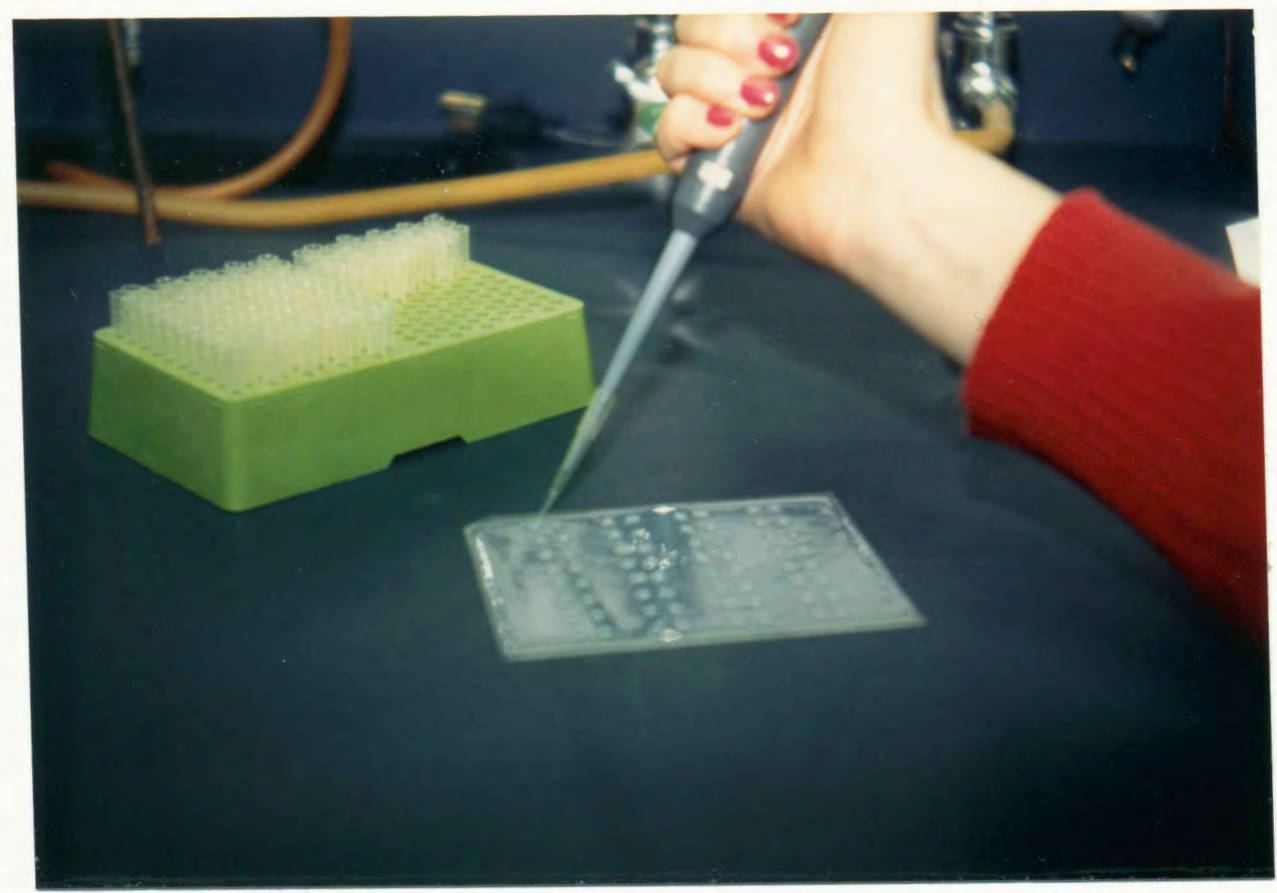

Figure 5. Filling wells in gel with specimen samples, controls, and anti-serum.

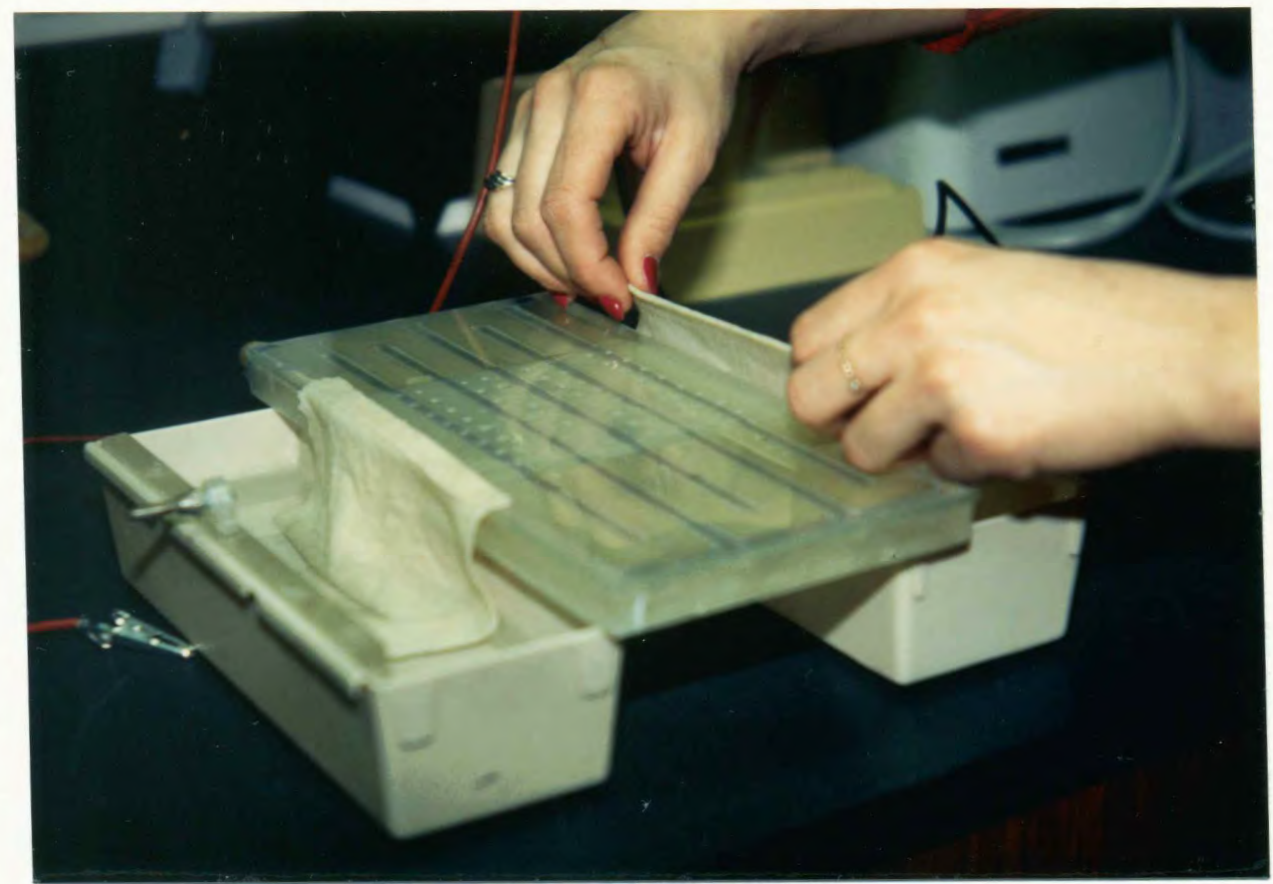

Figure 6. Placing wick material on end of gel for electrical contact. 


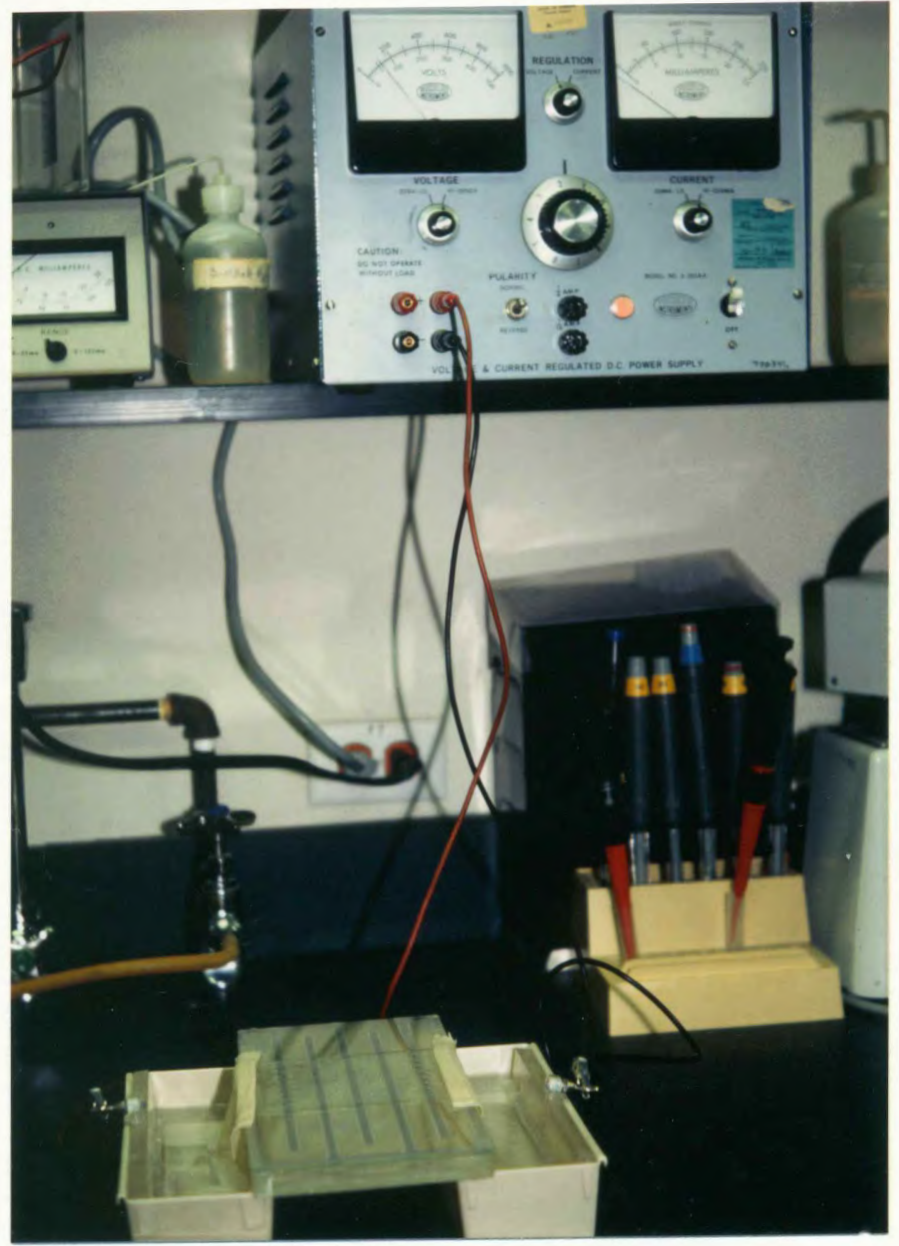

Figure 7. Gel is ready to run - complete electrophoresis set-up. 
Immediately after the electrophoresis the gel is blotted to remove excess proteins by covering it with two layers of filter paper wetted with distilled, deionized water, and then topped with several dry paper towels. It is then covered with a glass plate and a weight, such as a beaker or pan of water, is placed on top and then left for 10 minutes. If the blotting is omitted (as I did in ignorance when first starting the project) the excess protein in the antiserum makes dark blue haloes around the wells when the gel is stained, and this makes positives difficult to see.

After blotting, the gel is placed in a normal saline solution for 24 hours to salt out the precipitates from the positive controls and any positive reactions. This salting out helps remove excess proteins from the surface of the gel while making the precipitate from positive reactions more visible. The precipitates appear as white lines or arcs between the wells, and may be visible at this point, but often only the positive controls will show up prior to staining.

After the overnight saline bath the gel is placed in a distilled water bath to remove excess salt. Newman leaves it for an hour. I have had good luck simply putting the gel in the bath (a plastic box) on a rotator at slow speed for 15 minutes.

The next step is to dry the gels. Newman uses a drying 
oven for this purpose, and it takes about an hour and a half. On the advice of Dr. Everett Lovrien, whose lab space and equipment were used for this project, commercial hair dryers were used to dry the gels, which takes 15 minutes or less, if the gels are blotted again before drying. The corners of the gel are taped down to prevent curling during the drying process.

Once dry the gel is stained with coomassie blue, a standard protein stain. The solution used to mix the stain, and also used without the Coomassie as a final rinse, or destain, is methanol, distilled or deionized water, and glacial acetic acid mixed in a $2.5: 2.5: .5$ ratio. The stained gel is then a stable permanent record of the electrophoresis run.

\section{- CROSS-REACTIVITY PROTOCOL}

I had run well over 100 gels of Dietz artifact residues when I received a timely letter from Ms. Newman stating that she, in conjunction with the Immunology Department at the University of Calgary, had developed another step in the process; one designed to rule out cross-reactions, or false positives. Prior to receiving her letter, what had started as excitement at my results was quickly turning to despair and confusion over what was obviously an unreasonable number of positive reactions. Individual artifact samples were 
reacting to five or six widely different types of antisera, even before all of the antisera had been tried. Some, in fact, seemed to react with just about everything. It was obvious that I was observing cross-reactions rather than true reactions. Margaret had seemingly had a similar problem, which led to her working up a protocol to deal with it.

Immunoglobulin (antibody) molecules are $Y$ shaped structures, and the $\mathrm{V}$ portion of the $\mathrm{Y}$ (The Fab domain) is the variable portion which reacts with different antigens. The straight part of the $Y$ (The Fc domain) does not generally form binding sites for antigens. Sometimes parts of the antibody molecule will bind with portions of the antigen molecule that are merely somewhat similar rather than specific to the antibody, but there are ways to make the reaction more specific (Turgeon 1990).

In Newman's protocol each set of artifacts is run first against a non-immune serum; that is, simply the serum from some common animal, dried and prepared in the same ammonia solution as the control specimens. She used goat serum, and I used the same in adding the protocol to the analysis of the the Dietz site artifacts. Positive results to the nonimmune serum indicate that the reactivity is to the nonspecific portion of the antibody molecule rather than the specific sites on the molecule, and those false positives 
can then be ruled out (Newman 1988).

She then adds a non-ionic detergent (Tween 80) to those specimens that did not react to the non-immune serum, and this is intended to ..."eliminate cross-reactions and increase specificity. Positive reactions that occur after this step are true reactions." (Newman and Julig 1988).

This caused some major upheavals and changes in the original research design for this project. I had originally chosen to test all 282 of the Dietz site stone artifacts. This was based on the assumption that there might be residues in cracks and holes on the artifacts, even if not visible with the binocular microscope. In this respect the methodology of this project deviates from that of most other researchers who only test the artifacts that show visible residues, or that react with a dipstick test (e.g., Loy 1983a 1983b, Newman and Julig 1988, and Hyland et al. 1989 1990). I did not feel that enough was known about what might be recoverable on the artifacts to rule out testing any of them. It may eventually prove out that the visual analysis will indeed screen out unnecessarily testing a lot of specimens, although this particular project can, unfortunately, shed no light on this question, as will be explained in the Results section.

At the time the information about the cross-reactivity protocol was received from Ms. Newman, I had run two thirds 
(192) of the Dietz collection against almost all of the anti-sera. After discussing the problem with my advisor, it was decided that the most prudent course would be to concentrate on the last third of the collection, upon which little testing had as yet been done. Konemehu and Chimney Shelter were added later in the project, and the crossreactivity protocol was done for both of those collections before any further testing was done.

All of the artifacts in all three of the collections were tested against the non-immune serum, and no positives were encountered. A $1 \%$ solution of Tween 80 was then added to all of the specimens. Some of the earlier gels from the first two thirds of the Dietz collection that had reacted particularly strongly were re-run to see what the difference might be. Two sets from the Dietz site in particular, artifacts \#180 - 203, run against sigma rabbit and sheep anti-sera, demonstrated this difference quite profoundly. on the original run, out of those 24 specimens 21 reacted positively for both types of antisera (as well as some of them to other antisera). After the non-ionic detergent was added NONE of those reactions showed up. 
CHAPTER IV

RESULTS AND CONCLUSIONS

RESULTS

To be blunt, once the cross-reactivity protocol was added to the process, there were no positives whatsoever from the Dietz site samples. Fortunately, there were some positives from the other two sites.

of the 48 points in the collection from Konemehu, 17 reacted positively with avian (chicken) antiserum (see Figure 8). Some of those same points initially reacted with rat antiserum, but this disappeared for the most part when extra Tween was added and the artifacts re-run. The rat seems to have been a cross-reaction.

similar results were obtained from the three artifacts from the chimney Shelter site (see Figure 9). Since all three were initially sent un-numbered, they were arbitrarily assigned numbers 1,2 , and 3 . After the analysis was completed I recieved the just finished report on the site, and the artifacts could then be assigned the proper numbers. Artifact number 1 should be TP2-13, number 2 is TP2-14, and my assigned number 3 artifact is actually TP2-15.

specimen \#2 (TP2-14) from chimney shelter reacted with avian and rodent antisera. The rodent reaction disappeared 

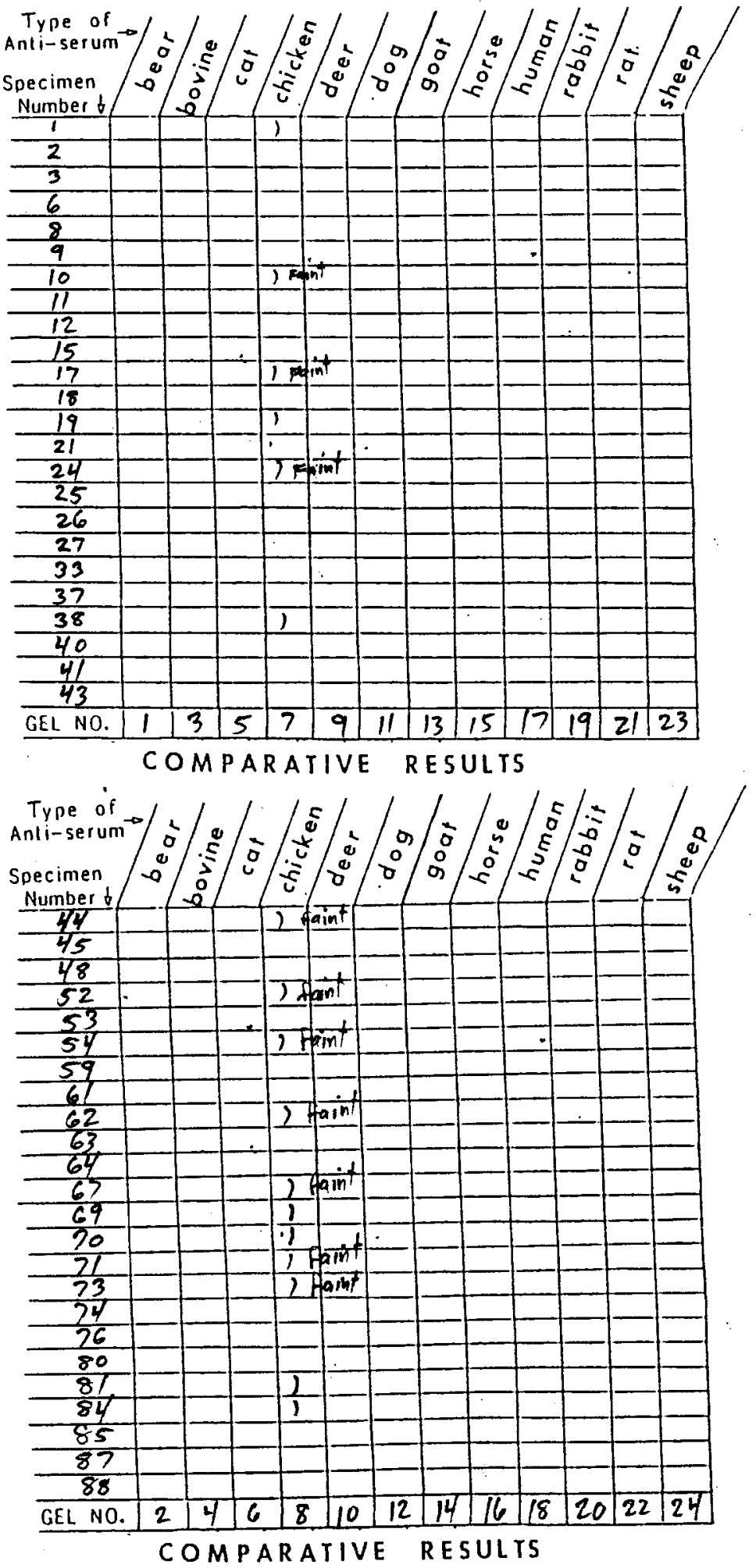

Figure 8. Comparative results from Konemehu. 


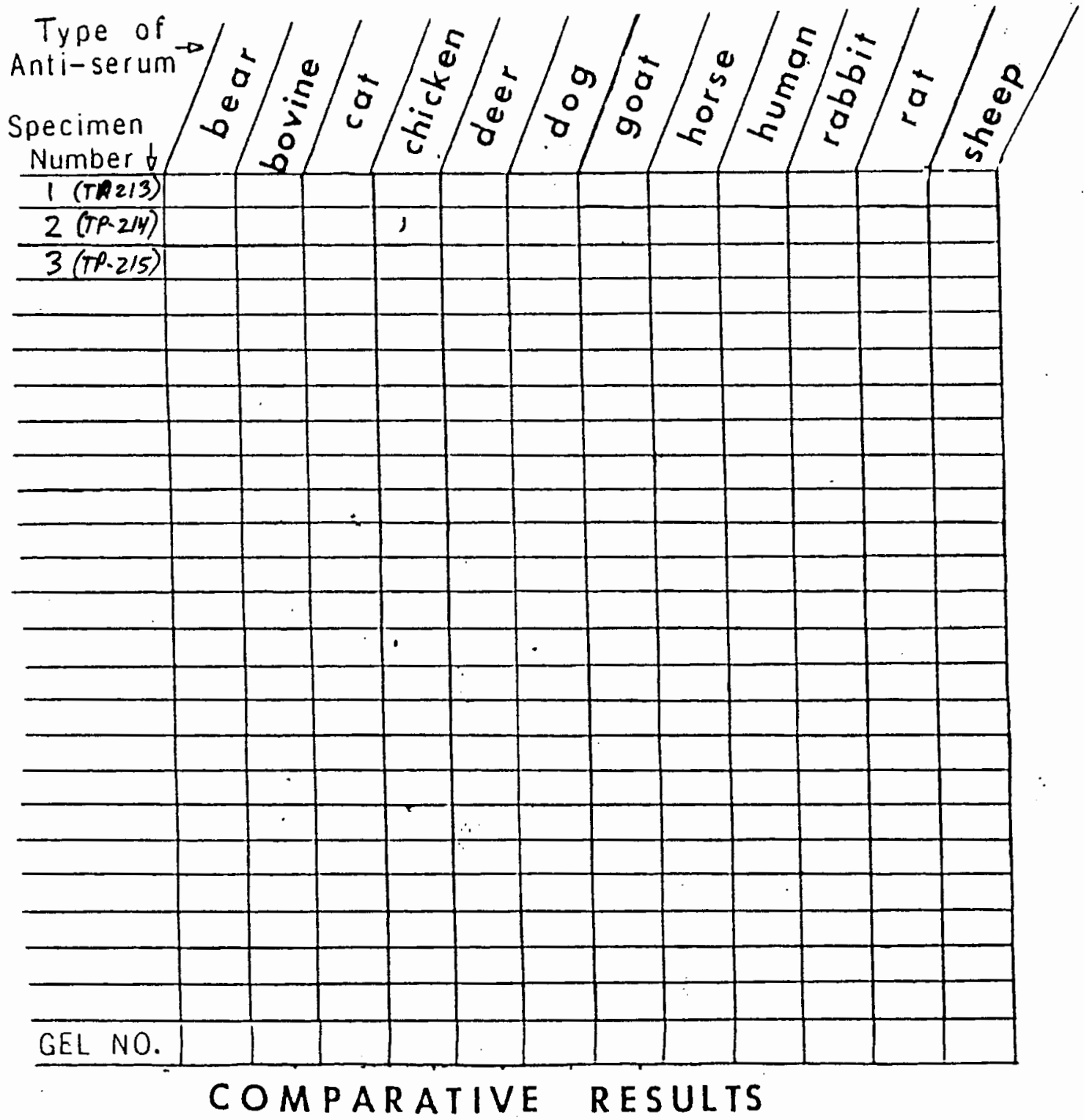

Figure 9. Comparative results from Chimney Shelter 
with the addition of more Tween. The rodent antiserum seems to have been particularly strong. Antisera vary greatly from each other in strength and specificity, even from the same company and from different lot numbers. This would account for extra detergent being needed to counteract cross-reactivity with one antiserum while a smaller amount was needed for all the others. Initially only 100 microliters was added to each specimen in order to keep from diluting the specimens too much. Apparently this amount was too conservative, and another 100 microliters was needed to take care of the problem. The positive control reactions remained strong for both rat and chicken, even though Tween had been added to the control specimens as well as the artifact specimens.

\section{DISCUSSION}

Vance Carlson, of the U.S. Forest Service, was familiar with the report of the results from Konemehu (Barr 1989b) before he sent the 3 artifacts from the Umpqua National Forest for testing. One of his comments was that for years point collectors had been calling such small points "bird points", while professional archaeologists had been unwilling to make such a claim (Carlson, personal communication, 1990). The results from the cross-over electrophoresis seem to support the point hunters in this 
case.

Konemehu had little faunal material except very fragmented deer bone (K. Winthrop, personal communication, 1989). Due to the even greater fragility of bird bone, it is unlikely that any would have survived, so it is particularly interesting that the cross-over electrophoresis demonstraterd the avian reactions.

It should be noted that the work for Winthrop Associates was for financial compensation. This funding helped pay for some of the supplies, such as extra methanol, acetic acid, and antisera for both that analysis and to help complete the Dietz site analysis.

There are several possibilities for the lack of positive results from the Dietz site. The specimens may simply have been in solution for too long. Although they were refrigerated, most were in solution for well over a year before the study was completed, and in hindsight should have been frozen when not in active use. The other two collections were processed and analyzed immediately, so the refrigeration would have been adequate for the short term preservation of the proteins in solution.

When I began the project, I was under the impression that some of the Dietz artifacts, particularly the clovis component of the collection, had been found in situ in a shallow but well defined stratigraphic context. According 
to Judy willig, who did the geology of the site, this was not necessarily the case. Many of the clovis artifacts were surface finds, and even the excavations were no more than about 20 centimeters deep (Willig 1988). The points had probably been repeatedly washed out and covered up over the course of the last 8,000 years (Willig, personal communication, 1990), and the effect of this on the blood residues is not likely to be very good.

The points, then, may simply have been much more weathered than anyone thought when this project was started. According to John Fagan, though, none of the points were very scratched or worn and none had developed an alkali coating (Fagan, personal communication, 1990). So, although the artifacts may have been repeatedly exposed on the ground surface over the last few thousand years, they were not as weathered as prolonged surface exposure would have left them.

Normally, soil samples from a site are tested as well as the artifacts. This is done to show that more recent contaminants in the soil are not causing positive reactions rather than the actual residues on the artifacts themselves. As mentioned earlier, rodent urine has been detected in a possible archaeological setting (Lowenstein, personal communication, 1987). Since no positives were found with the Dietz site collection, it was decided to forego testing 
soil samples, as it would only have added an unnecessary step.

Six soil samples were tested from Konemehu, and very faint avian reactions were detected on two of them. These reactions may indicate modern contamination in the soils, or they may indicate that the site was the focus of the butchery of the same animals that had been hunted with the points found at the site (Barr 1989b). A more thorough description of the site could help clarify this point, but this is unavailable at this time. No soil samples were available from Chimney Shelter.

Very little is yet known about the effects of soil chemistry on blood residue preservation. It should be pointed out that many of the successes of residue analysis have been from acid soils, and that the Dietz site is very alkaline. The effect of soil chemistry on residue preservation is still unknown, and warrants further research.

The preservation of some proteins can differ widely, even within a single site. Gilbert, Lowenstein and Hesse (1990), using RIA, determined that equid bones from the same animal showed differences in protein preservation (collagen and albumin). These variations appeared to be due to differences in the soils and taphonomic deposition within the site. 
In one of his most recent papers, Loy (LOY and Wood 1989) mentions the possibility of problems in preservation of liquid samples, especially those taken under field conditions and without refrigeration. He had no problems with the specimens stored under either refrigerated or nonrefrigerated conditions, but he did not mention how long they had been stored; presumably just for shipping from Turkey to Australia where he now works.

The Dietz site specimens may have simply broken down in the up to 2 years during which many of them were refrigerated. The specimens had the dirt and whatever else had been on the artifacts' surfaces when collected. Bacterial growth could have effected the reactivity of the proteins that might have been there by breaking them down. It is possible that at some future date, if the artifacts have not been thoroughly washed, the untested sides of the artifacts could still be tested. The liquid specimens used in this study are now frozen, and perhaps further testing could be done on them with other more sensitive techniques, and after my own knowledge on the subject has increased. There is a case to be made that there may not have been anything there to pick up in the first place. That the artifacts were primarily surface finds, or only shallowly covered before being excavated may lend some weight to this. Much, much more needs to be researched on the types of soils 
and environments conducive to the preservation of blood residues on stone artifacts, but that is more than this, or any single paper or project could address at this time.

Perhaps, too, there simply was not enough specimen present to be picked up by the technique of cross-over electrophoresis. Another more sensitive technique might have detected what it could not. As mentioned earlier, Jerold Lowenstein did test some of the artifacts by RIA at the beginning of this study when the specimens were still fresh. He detected only a few possible positives out of fifty or so artifacts, even with the much more sensitive technique. Again, I hope to have the chance to re-test the Dietz site artifacts at another time and with a different technique.

To summarize, the lack of positive results from the Dietz site could have been due to: 1. The liquid specimens may have been in storage for too long before testing. 2. The effects of weathering on the artifacts, may have destroyed residues that may have existed at one time. (Most positve results, such as my own from Konemehu (Barr 1989b) and Chimney Shelter, and from the work that Newman and others have done, have been from relatively undisturbed sites.) 3 . The soil chemistry may not have been conducive to the preservation of residues in the first place. 4. The residues may be present, but in such minute amounts that 
cross-over electrophoresis may not be sensitive enough to detect them where it might be possible to with another, more sensitive technique.

\section{BLOOD RESIDUE ANALYSIS: THE FUTURE}

I originally envisioned cross-over electrophoresis as a relatively inexpensive generalized screening test for other, more specific tests. As such cross-over electrophoresis would narrow the results down to family group, and other, more expensive tests (in terms of both money and amount of specimen available) such as RIA or EIA, could begin from there, rather than from scratch, to identify the species. This is still a possibility as the results from Konemehu and Chimney Shelter sites indicate. Those results did show the potential to discover something about the faunal component of a site using cross-over electrophoresis that could not have been discovered from the excavation and examination of bones alone.

Although one facet of this research has been somewhat disappointing, much has been learned in other ways, and new areas of investigation have opened up since this project was started in 1983. The original decision to look into an immunologically based test appears to have been a sound one. All of the major research being done in the field of blood residue analysis now has an immunological basis (or 
component, as Tom Loy has added an immunological component to his work with hemoglobin crystallization).

EIA is particularly promising at this time. Its expense may not be as great as originally thought, and it holds promise as a possible field test.

Other questions I had hoped to address with the information from the Dietz site still need to be addressed. In addition to the questions and needed areas of future research already presented, others remain. such as: what type of stone is best suited to preserving residues? Loy $(1983 a \& b)$ stated that an electrostatic reaction between the blood proteins and silicates in the stone is the process that keeps the residues in place for such long periods of time. Other work is being done now to further examine the exact mechanism (Hyland et al. 1990) or mechanisms at work in this process. The coarseness and type of stone may be a factor as well, and is one question I had hoped to address with the Dietz site material.

Another question I had hoped to look at was whether the Clovis people relied primarily on large game, or if they also utilized small game. These questions and others must be answered with further research, but blood residue analysis does offer a way to deal directly with some of them where educated guesses had previously been the only tool for approaching such 
1questions.

The field of blood residue analysis is still promising, and still in its infancy, although growing rapidly. It has been a pleasure, however frustrating at times, to work on this project and in this field. I hope to continue working in it in one way or another in the future, for I believe in its potential to answer old questions and to open up new information about our past. 


\section{REFERENCES}

Andrew, w. 1965. "Comparative Hematology," Grove and stratton, New York

Barr, Shirley J. 1989a. "Blood From Stones: Blood Residue Analysis of the Dietz Site Clovis Artifacts," paper presented at the 54 th annual Society for American Archaeology conference, Atlanta, Georgia

Barr, Shirley J. 1989b. "Blood Residue Analysis of the Artifacts from Konemehu: Northern California," unpublished research report done for winthrop Associates, Ashland, OR

Brieur, Frederick L. 1976. "New Clues to Stone Tool Function: Plant and Animal Residues," American Antiquity, vol. 41:478-484

Broderick, Michael 1979. "Ascending Paper Chromatographic Technique in Archaeology," from "Lithic Use-Wear Analysis," edited by Bryan Hayden. Academic Press, New York, San Francisco, and London

Culliford, Bryan J. 1971. "The Examination and Typing of Bloodstains in the Crime Laboratory," U.S. National Institution of Law Enforcement and Criminal Justice, Washington, D.C. - U.S. Government Printing office

Custer, Jay F., John Ilgenfritz, and Keith R. Doms 1988. "A Cautionary Note on the Use of Chemstrips for the Detection of Blood Residues on Prehistoric Stone Tools," Journal of Archaeological Science, vol. 15:343-345

Dorrill, Marion and P.H. Whitehead 1979. "The Species Identification of Very old Human Bloodstains," Forensic Science International, vol. 13:111-116

Downs, Elinor F. 1985. "An Approach to Detecting and Identifying Blood Residues on Archaeological stone Artifacts: A Feasibility study," Center for Materials Research in Archaeology and Ethnology, Massachusetts Institute of Technology, Cambridge, MA (unpublished paper) 
Fagan, John L. 1988. "Clovis and Western Pluvial Lakes Tradition Lithic Technologies at the Dietz Site in Southcentral Oregon," in "Early Human Occupation in Far Western North America: The Clovis-Archaic Interface," edited by J.A. Willig, C.M. Aikens, and J.L. Fagan, Nevada State Museum Anthropological Papers, No. 21, Carson City, Nevada

Fiedel, Stuart J. 1987. "Prehistory of the Americas," Cambridge University Press, Cambridge, London, New York

Gaensslen, R.E. 1983. "Sourcebook in Forensic Serology, Immunology, and Biochemistry," U.S. Government Printing office

Gilbert, Allan S., Jerold M. Lowenstein, Brian C. Hesse 1990. "Biochemical Differentiation of Archaeological Equid Remains: Lessons from a First Attempt," Journal of Field Archaeology, vol. 17:39-48

Gurfinkel, D.M. 1987 "Difficulties Associated With the Analysis of Organic Archaeological Residues," paper presented at the 52d annual society for American Archaeology Conference in Toronto, Canada

Hyland, D.C., J.M. Adovasio, J.M. Tersak, M.I. Siegal and K.W. Carr 1989. "A New Technique for the Identification of Residual Blood on Artifactual Materials," paper presented at the 54 th annual Society for American Archaeology Conference in Atlanta, Georgia

Hyland, D.C., J.M. Tersak, J.M. Adovasio and M.I. Siegal 1990. "Identification of the Species of Origin of Residual Blood on Lithic Material," American Antiquity, vol. 55, no.1 pp. 104-112

Kind, S.S. and Rosalyn M. Cleevely 1969. "The Use on Ammoniacal Bloodstain Extracts in ABO Groupings," Journal of the Forensic Science Society, vol.9:131-139

Lee, H.C. and P.R. DeForest 1976. "A Precipitin Inhibition Test of Denatured Bloodstains for the Determination of Human Origin," Journal of Forensic Sciences, vol. 21, no. 1 pp. 804-811

Lowenstein, Jerold M. 1985. "Molecular Approaches to the Identification of Species," American Scientist, vol.73, Nov.-Dec., pp.541-547

LoY, T.H. 1983a."Prehistoric Blood Residues: Detection on Tool Surfaces and Identification of Species of origin," Science, vol. 220:1269-1271 
Loy, T.H. 1983b. "Prehistoric Use-Residue Analysis:

Reconstruction of Processes and Events in the Past, " paper presented at the ICAES Conference in Vancouver, B.C., Canada

Loy, Thomas H. and Andree R. Wood 1989. "Blood Residue Analysis at Cayonu Tepes, Turkey," Journal of Field Archaeology, vol. 16:451-460

Loy, T.H., Rhys Jones, D.E. Nelson, Betty Meehan, John Vogel, John Southon and Richard Cosgrove 1990.

"Accelerator Radiocarbon Dating of Human Blood Proteins in Pigments from Late Pleistocene Art Sites in Australia," Antiquity, vol. 64:110-116

Mehringer, Peter J. Jr. 1988a. "Clovis Cache Found: Weapons of Ancient Americans," National Geographic, 174(4):500-503

Mehringer, Peter J. Jr. 1988b. "The Richey-Roberts Clovis Cache, East Wenatchee, Washington," Northwest Science $62(5): 271-272$

Minor, Rick and Robert R. Musil 1990. "Determination of Eligibility statemant for Chimney Shelter (35DO440)"

Newman, Margaret and Patrick Julig 1988. "Report on Blood Residue Analysis of Artifacts from the Cummins site, Thunder Bay, Ontario," paper presented at the C.A.A conference in Whistler, British Columbia, April 1988

Prager, Ellen M., A.C. Wilson, J.M. Lowenstein, and V.M. Sarich," Mammath Albumin," Science, vol. 209:287-289

Reichert, E. and A. Brown 1909. "The Crystallography of Hemoglobins," Publication \#16, Carnegie Institute of Washington, Washington D.C.

Sensabaugh, G.F., A.C. Wilson, and P.L. Kirk 1971."Protein Stability in Preserved Biological Remains" International Journal of Biochemistry, 2:558-568

Shafer, Harry J. and Richard G. Holloway 1979. "Organic Residue Analysis in Determining stone Tool Function," from "Lithic Use-Wear Analysis," edited by Brian Hayden, Academic Press, New York, San Francisco and London

Tennant, winston and Laura Tennant 1987. "Chemical Analysis of Organic Residues on Stone Tools," paper presented at the 4 oth Northwest Anthropological Conference on March 24, 1987 in Gleneden Beach, OR 
Turgeon, Mary Louise 1990. "Immunology and Serology in Laboratory Medicine," The C.V. Mosby Company, st. Louis, Baltimore, Philadelphia, and Toronto

Washino, R. 1977. "Identification of Host Blood Meals in Arthropods," U.S. Army Medical Research and Development Command, washington D.C.

willig, Judith A. 1988. "Paleo-Archaic Adaptations and Lakeside Settlement Patterns in the Northern Alkali Basin," in "Early Human Occupation in Far Western North America: The Clovis-Archaic Interface," edited by J.A. Willig, C.M. Aikens, and J.L. Fagan, Nevada State Museum Anthropological Papers, no. 21, Carson City, Nevada

Wyckoff, R.W.G. 1972. "The Biochemistry of Animal Fossils," Williams and Wilkins, New York 


\title{
APPENDIX A
}

\author{
FORMS
}

(All forms shown are $3 / 4$ actual size) 
ARTIFACI ANALYSIS

Specimen

TOOL TYPE:

SURFACE:

MATERIALS :

LEVEL :

EXTRACTION SOLUTION:

EXTRACTTION TIME:

AMOUNT USED:

MICROSCOPY

RED BLOOD CELLS? FIBRES OR TISSUES?

GENERAL DESCRIPTION:

CROSS-OVER ELECTROPHORESIS RESULTS:

GEL NUMBERS : 


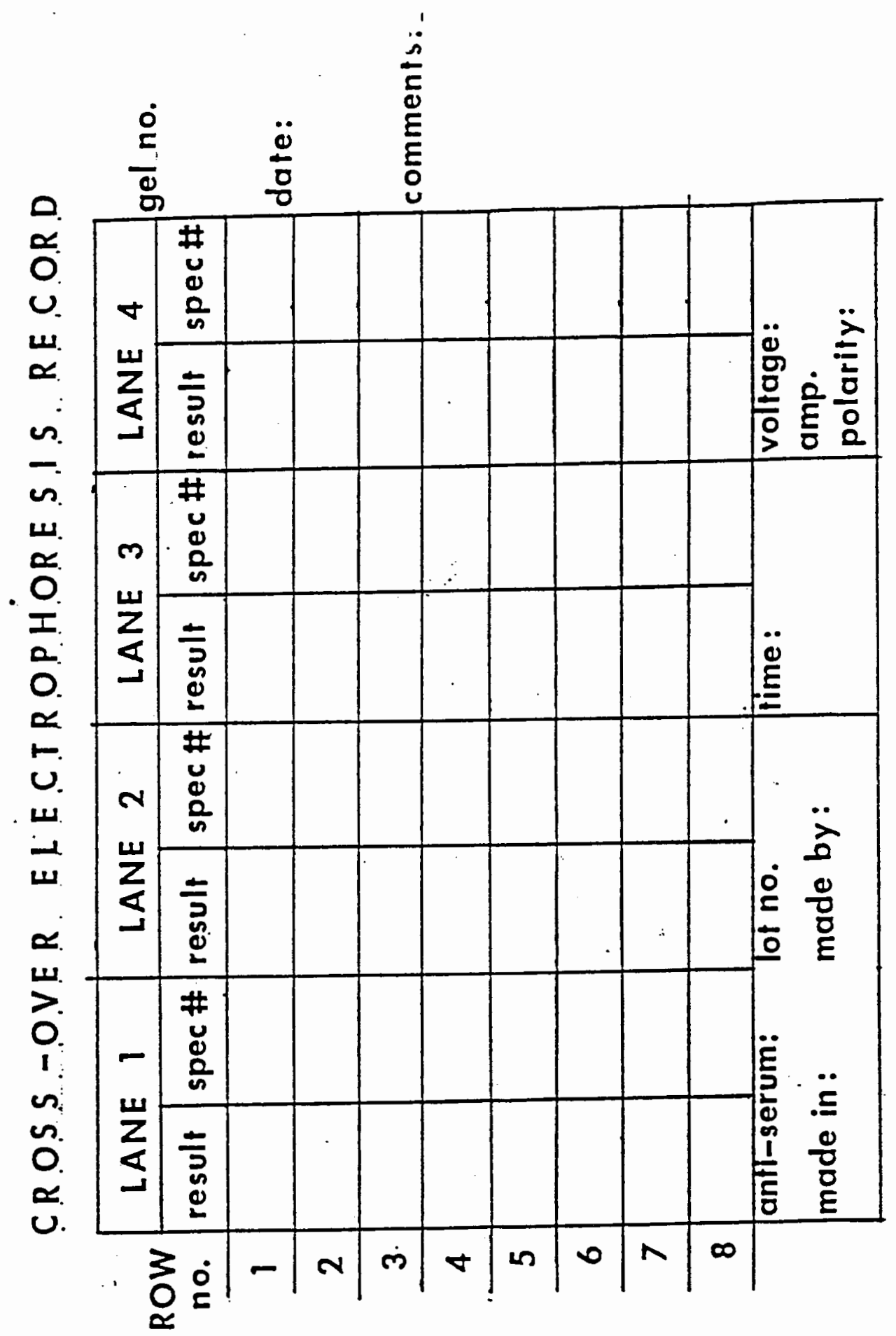




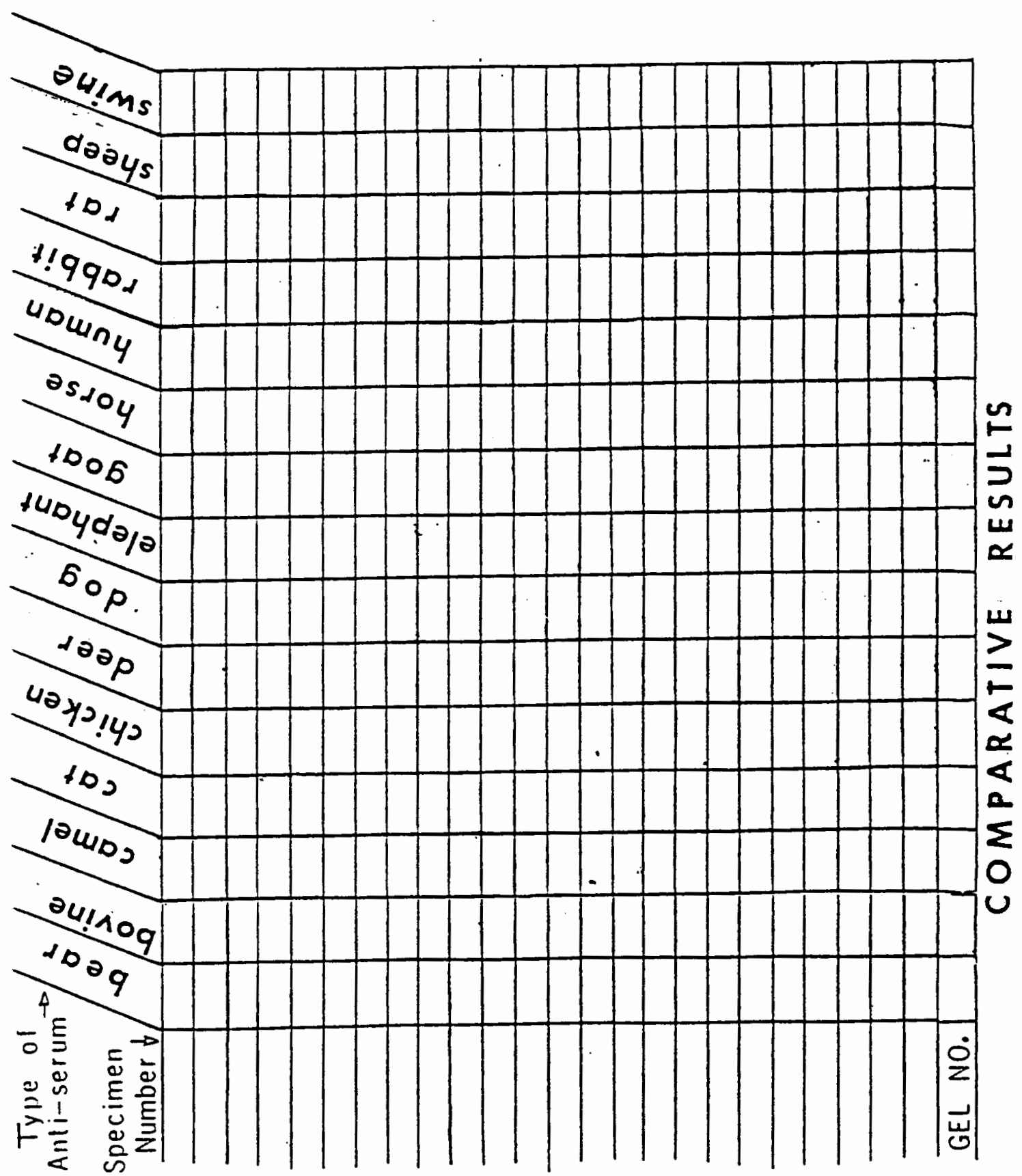


APPENDIX B

METHODOLOGY OUTLINE 
APPENDIX B

METHODOLOGY - OUTLINE

I.VISUAL ANALYSIS

A. Make outline drawing of artifact on analysis form.

B. Fill in all other information on form (artifact \#, etc.).

C. Examine all edges and surfaces of artifact with binocular microscope.

D. Note any areas of possible residues on drawing on form.

II. EXTRACTION OF RESIDUES

A. Wash and dry weigh boats with RB 50, or similar detergent.

B. Place side of artifact to be tested face down in weigh boat.

C. Note side of artifact tested on analysis form.

D. Pipette measured amount of $5 \%$ ammonia solution or distilled water under the artifact.

E. Fill ultrasonic cleaner $1 / 2$ full with tap water.

F. Carefully place weigh boat with artifact in ultrasonic cleaner.

G. Turn on ultrasonic cleaner, and time for 5 minutes.

H. Number storage tube while ultrasonic is processing.

I. Shut off ultrasonic after 5 minutes are up, and then pipette off the solution into the storage tube.

$\mathrm{J}$. If artifact is large, note approximate area covered by solution on drawing on artifact analysis form.

K. If large number of artifacts are being processed at one time, change water in ultrasonic cleaner every $1 / 2$ hour (water will heat up, otherwise).

L. Refrigerate or freeze extracted solutions.

III. ELECTROPHORESIS

A. Preliminary steps

1. Make Barbital buffer - 1 vial of powder per liter.

2. Cut Gel Bond to correct size - $100 \mathrm{~mm}$ X $125 \mathrm{~mm}$.

3. Make 1 normal saline solution, store at room temp.

4. Make up de-stain in advance, store at room temp.

(methanol, distilled/ or deionized water, acetic acid in $2.5: 2.5: .5$ ratio).

B. Make gel(s) at least 1 day in advance of electrophoresis

1.measure .2 gm high EEO agarose per gel with $20 \mathrm{ml}$. barbital buffer, into large tube.

2 .boil in double boiler for 5 to 10 minutes

3. while mixture boiling, prepare hot plate and and Gel

Bond on glass plate. Pre-warm glass plate before pouring gel

4.pour hot agarose onto pre-warmed Gel Bond on glass plate

5.allow to cool for 10 to 15 minutes before moving 
6. prepare humid chamber

a.use clean plastic box with tight lid

b. Iine bottom of box with clean paper towels

c.dampen paper towels, and make sure they lie flat

d.with piece of tape, label lid with with date gel made

7. when gel cool, place in humid chamber and refrigerate (min. 24 hours)

8.after refrigerating, use metal punch and template pattern to create wells in gel

9.suction out gel plugs created in punching with vacuum pipette

C. Fill out electrophoresis run record form and place specimen tubes on top (to insure specimens stay in proper order).

D. Add specimens, controls, and anti-serum to appropriate wells

E. Pour barbital buffer into troughs for electrophoresis

F. Wet electrophoresis platform with water

G. Place gel(s) on platform between troughs

H. Dampen flannel wicks in buffer in troughs, and smooth one end of one wick over each end of gel

I. Hook up electrodes to each trough

$\mathrm{J}$. Turn on power, run at 130 volts for 40 to 45 minutes

K. Shut off power

L. Blot gels with moist filter paper

M. Put saline solution in box from humid chamber after removing paper towels

$\mathrm{N}$. Place blotted gel in saline solution and leave for $24 \mathrm{hrs}$.

0 . After saline bath, place gel in distilled water and rotate for 15 minutes.

P. Blot rinsed gel

Q. Dry gel

1. tape down corners of gel

2. adjust dryers and turn them on

3. move dryers as needed during drying process

R. Mix stain (.1 gm per $200 \mathrm{ml}$. of de-stain)

S. Stain gel for $1 / 2 \mathrm{hr}$.

T. De-stain gel for several minutes, until background clear

U. Number gel and record results, if any, on electrophoresis record form.

v. Add results to comparative results form. 